\title{
Analyses of the OSU-MASLWR Experimental Test Facility
}

\author{
F. Mascari, ${ }^{1}$ G. Vella, ${ }^{1}$ B. G. Woods, ${ }^{2}$ and F. D'Auria ${ }^{3}$ \\ ${ }^{1}$ Dipartimento dell'Energia, Università degli Studi di Palermo, Viale delle Scienze, Edificio 6, 90128 Palermo, Italy \\ ${ }^{2}$ Department of Nuclear Engineering \& Radiation Health Physics, Oregon State University, 116 Radiation Center, \\ Corvallis, OR 97331-5902, USA \\ ${ }^{3}$ San Piero a Grado Nuclear Research Group (SPGNRG), Università di Pisa, Italy
}

Correspondence should be addressed to F. Mascari, mfulvio78@yahoo.it

Received 30 July 2011; Accepted 25 October 2011

Academic Editor: Alessandro Del Nevo

Copyright ( 92012 F. Mascari et al. This is an open access article distributed under the Creative Commons Attribution License, which permits unrestricted use, distribution, and reproduction in any medium, provided the original work is properly cited.

Today, considering the sustainability of the nuclear technology in the energy mix policy of developing and developed countries, the international community starts the development of new advanced reactor designs. In this framework, Oregon State University (OSU) has constructed, a system level test facility to examine natural circulation phenomena of importance to multi-application small light water reactor (MASLWR) design, a small modular pressurized water reactor (PWR), relying on natural circulation during both steady-state and transient operation. The target of this paper is to give a review of the main characteristics of the experimental facility, to analyse the main phenomena characterizing the tests already performed, the potential transients that could be investigated in the facility, and to describe the current IAEA International Collaborative Standard Problem that is being hosted at OSU and the experimental data will be collected at the OSU-MASLWR test facility. A summary of the best estimate thermal hydraulic system code analyses, already performed, to analyze the codes capability in predicting the phenomena typical of the MASLWR prototype, thermal hydraulically characterized in the OSU-MASLWR facility, is presented as well.

\section{Introduction}

Today, considering the sustainability of the nuclear technology in the energy mix policy of developing and developed countries, the international community, taking into account the operational experience of the nuclear reactors, starts the development of new advanced reactor designs. Some of the new nuclear reactor designs use passive safety systems based on the use of the natural circulation for the cooling of the core during the designed operational condition and for the removing of the residual heat during transient conditions [1-5]. Emergency systems based on natural circulation are considered, for example, in the AP600/1000 design, WWER1000/V-392 and WWER-640/V-407 designs, AC-600 design, SMART design, IRIS design, SWR 1000 MWe design, and in the ESBWR design [4-7]. Examples of reactors that rely on natural circulation for the removing of the core power during normal operation are the MASLWR, the ESBWR, the SMART, and the CAREM design [5-7].

The MASLWR integral reactor concept [1, 2, 8-13], developed by Idaho National Engineering and Environmental Laboratory, OSU, and NEXANT—Bechtel, Figure 1, is a small modular PWR relying on natural circulation during both steady-state and transient operation, which includes an integrated steam generator (SG) consisting of banks of vertical helical tubes contained within the reactor pressure vessel (RPV). The primary coolant flows outside the SG tubes and the feed-water (FW) is fully vaporized resulting in superheated steam at the SG exit. The MASLWR module has a net output of $35 \mathrm{MWe}$, and a number of modules could be built in increments, in a "field" concept, to generate electricity in larger electricity grids $[8,11]$.

OSU has constructed, under a US Department of Energy grant, a system-level test facility, OSU-MASLWR [1, 2, 8-13], to examine natural circulation phenomena of importance to the MASLWR design. Four tests have been conducted in support of the MASLWR concept design verification.

Considering the thermal hydraulic phenomena simulating capability of this facility, the planned work will be not only to specifically investigate the MASLWR concept design further but also to advance the broad understanding of integral natural reactor plants and accompanying passive safety features as well. 


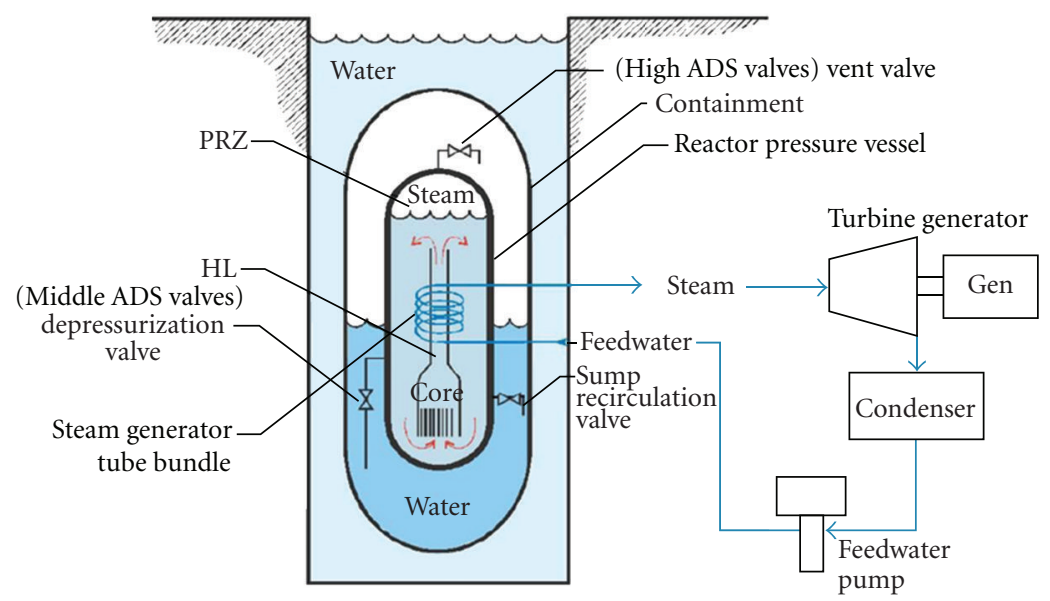

FIgURE 1: MASLWR conceptual design layout $[1,2,8,11,13]$.

After the completion of the first test series, through a grant from the International Atomic Energy Agency (IAEA), the OSU-MASLWR test facility core was reconfigured to eliminate a recurring grounding problem and improve facility reliability [12] in anticipation of conducting an IAEA ICSP on "Integral PWR Design Natural Circulation Flow Stability and Thermo-hydraulic Coupling of Primary System and Containment During Accidents" [14-16]. This ICSP is being hosted at OSU and the experimental data will be collected at the OSU-MASLWR facility, to provide experimental data on single-/two-phase flow instability phenomena under natural circulation conditions and coupled containment/ reactor vessel behavior in integral type light water reactors.

The target of this paper is to give a review of the main characteristics of the experimental facility, to analyse the main phenomena characterizing the tests already performed, the potential transients, of interest for integral reactor types, that could be investigated in the facility, and to describe the current IAEA ICSP. A summary of the best estimate thermal hydraulic system code analyses, already performed, to investigate the codes capability in predicting the phenomena typical of the MASLWR prototype, thermal hydraulically characterized in the OSU-MASLWR facility, is presented as well.

\section{MASLWR Design}

2.1. MASLWR Overview. The MASLWR [1, 2, 8-13], Figure 1, is a small modular integral PWR relying on natural circulation during both steady-state and transient operations. The use of natural circulation reduces the number of active components simplifying the configuration of nuclear steam supply system.

The RPV contains the core, the pressurizer (PRZ), and an integrated SG consisting of banks of vertical helical tubes located in the upper region of the vessel outside of the hot leg (HL) chimney. The MASLWR steady-state operating conditions are reported in Table 1.

The RPV is surrounded by a cylindrical containment, partially filled with water. This containment provides pressure suppression and liquid makeup capabilities and is submerged in a pool of water that acts as the ultimate heat sink.
TABLE 1: MASLWR steady-state operating conditions [8-10].

\begin{tabular}{lc}
\hline Primary side & \\
Reactor thermal power & $150 \mathrm{MW}$ \\
Primary pressure & $7.60 \mathrm{MPa}$ \\
Primary mass flow rate & $597 \mathrm{~kg} / \mathrm{s}$ \\
Reactor inlet temperature & $491.80 \mathrm{~K}$ \\
Reactor outlet temperature & $544.30 \mathrm{~K}$ \\
Saturation temperature & $565 \mathrm{~K}$ \\
Reactor outlet void fraction & $0.00 \%$ \\
\hline Secondary side & \\
Steam pressure & $1.50 \mathrm{MPa}$ \\
Steam outlet quality & 1 \\
Steam temperature & $481.40 \mathrm{~K}$ \\
Saturation temperature & $471.60 \mathrm{~K}$ \\
Feedwater temperature & $310 \mathrm{~K}$ \\
Feedwater flow rate & $56.10 \mathrm{~kg} / \mathrm{s}$ \\
\hline
\end{tabular}

The RPV can be depressurized using the automatic depressurization system (ADS), consisting of six valves discharging into various locations within the containment. In particular two independent vent valves (high ADS valve), two independent depressurization valves (middle ADS valve) and two independent sump recirculation valves are considered in the MASLWR design.

2.2. MASLWR SBLOCA Phenomenology Description. Considering the MASLWR integral arrangement, there are not pressurized primary components outside the RPV; therefore the possibility of large-break loss of coolant accident (LOCA) is eliminated and the small-break LOCA (SBLOCA) initiating events are reduced. Of particular interest is the SBLOCA passive mitigation strategy typical of the MASLWR design.

Following, for example, an inadvertent opening of an ADS valve, a primary side blowdown into the pressure suppression containment takes place. The RPV blowdown causes a primary pressure decrease and a consequent containment pressure increase causing a safety injection signal. It 


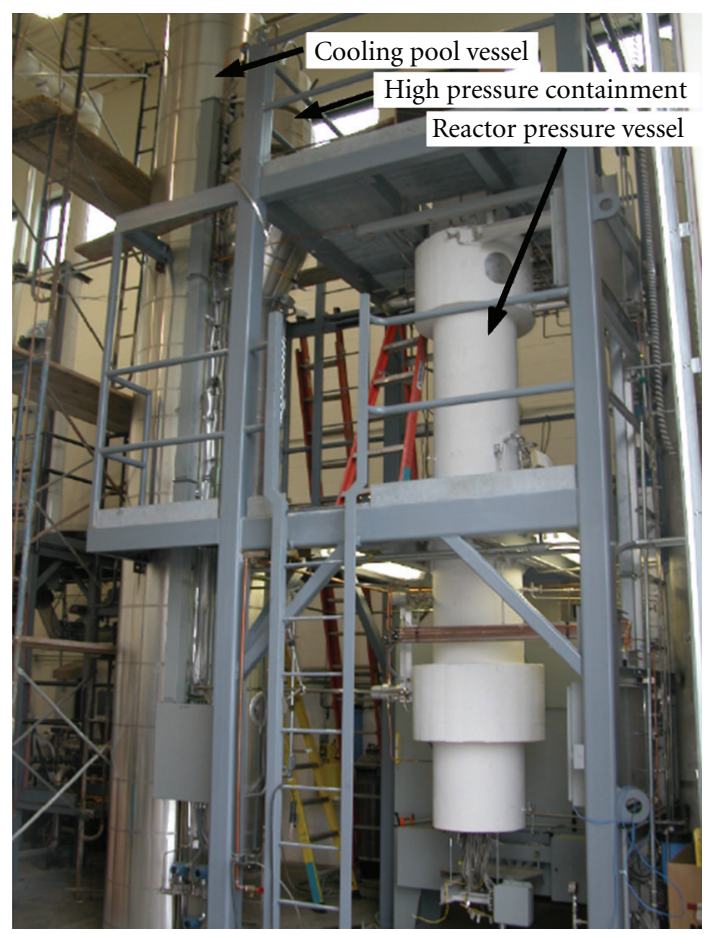

FIGURE 2: OSU-MASLWR experimental facility photo $[1,2,13]$.

automatically opens, Figure 1, the high ADS valves, the middle ADS valves, and the sump recirculation valves. As the primary and the containment pressures become equalized, the blowdown is terminated and a natural circulation flow path is established. In fact when the sump recirculation valves are opened, the vapour produced in the core goes in RPV upper part and, through the high ADS valve, goes to the containment where it is condensed. At this point through the sump recirculation lines and the downcomer, the fluid goes to the core again. The pressure suppression containment is submerged in a pool that acts as the ultimate heat sink. This mechanism permits the cooling of the core during the transient [8-11].

\section{Description of the OSU-MASLWR Facility}

3.1. OSU-MASLWR Test Facility. In the development process of advanced nuclear reactors, the analysis of single- and twophase fluid natural circulation in complex systems $[5,10,17-$ 19], under steady-state and transient conditions, is crucial for the understanding of the physical and operational phenomena typical of these advanced designs characterized by the interaction between different parts of the system. The use of experimental facilities is fundamental in order to characterize the thermal hydraulics of these phenomena and to develop an experimental database useful for the validation of the computational tools necessary for the operation, design, and safety analysis of nuclear reactors.

In general it is expensive to design a test facility to develop experimental data useful for the analyses of complex system; therefore reduced scaled test facilities are in general used to characterize them. Since the experimental data

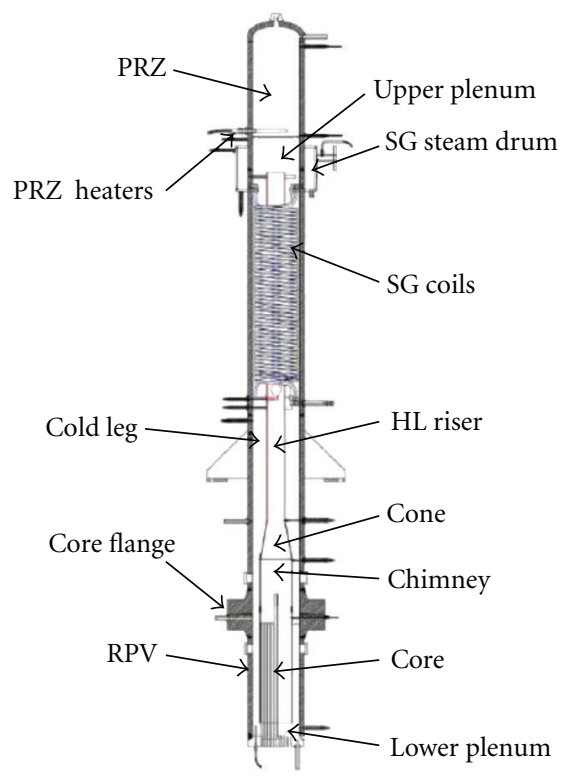

Figure 3: RPV internal components $[1,2,11,13]$.

produced have to be applicable to the full-scale prototype, the geometrical characteristics of the facility and the initial and boundary condition of the selected tests have to be correctly scaled. Since possible scaling distortions are present in the experimental facility design, the similitude of the main thermal hydraulic phenomena of interest has to be assured permitting their accurate experimental simulation $[10,11$, $18,19]$.

OSU has constructed, under a US Department of Energy grant, a system-level test facility to examine natural circulation phenomena of importance to MASLWR design. The scaling analyses of the OSU-MASLWR experimental facility was performed in order to have an adequate simulation of the single- and two-phase natural circulation, reactor system depressurization during a blowdown and the containment pressure response typical of the MASLWR prototype. The model used for the scaling analyses performed in $[9,10]$ is partly drawn from the USNRC's Severe Accident Scaling Methodology (SASM) presented in NUREG/CR-5809 [19]. The detailed OSU-MASLWR scaling analyses is reported in $[9,10]$.

As a result of the scaling analyses, the OSU-MASLWR test facility $[8-13,18,19]$, shown in Figure 2 , is scaled at $1: 3$ length scale, $1: 254.7$ volume scale, and $1: 1$ time scale, is constructed entirely of stainless steel, and is designed for full pressure and full temperature prototype operation. It includes the primary circuit, consisting of the RPV and ADS lines, the secondary circuit, and the containment structures. In addition to the physical structures that comprise the test facility, there are data acquisition, instrumentation, and control systems. Auxiliary lines and systems are present in the facility.

3.2. OSU-MASLWR RPV Overview. The internal components of the RPV $[1,2,8-13]$, Figure 3, are the core, the HL 


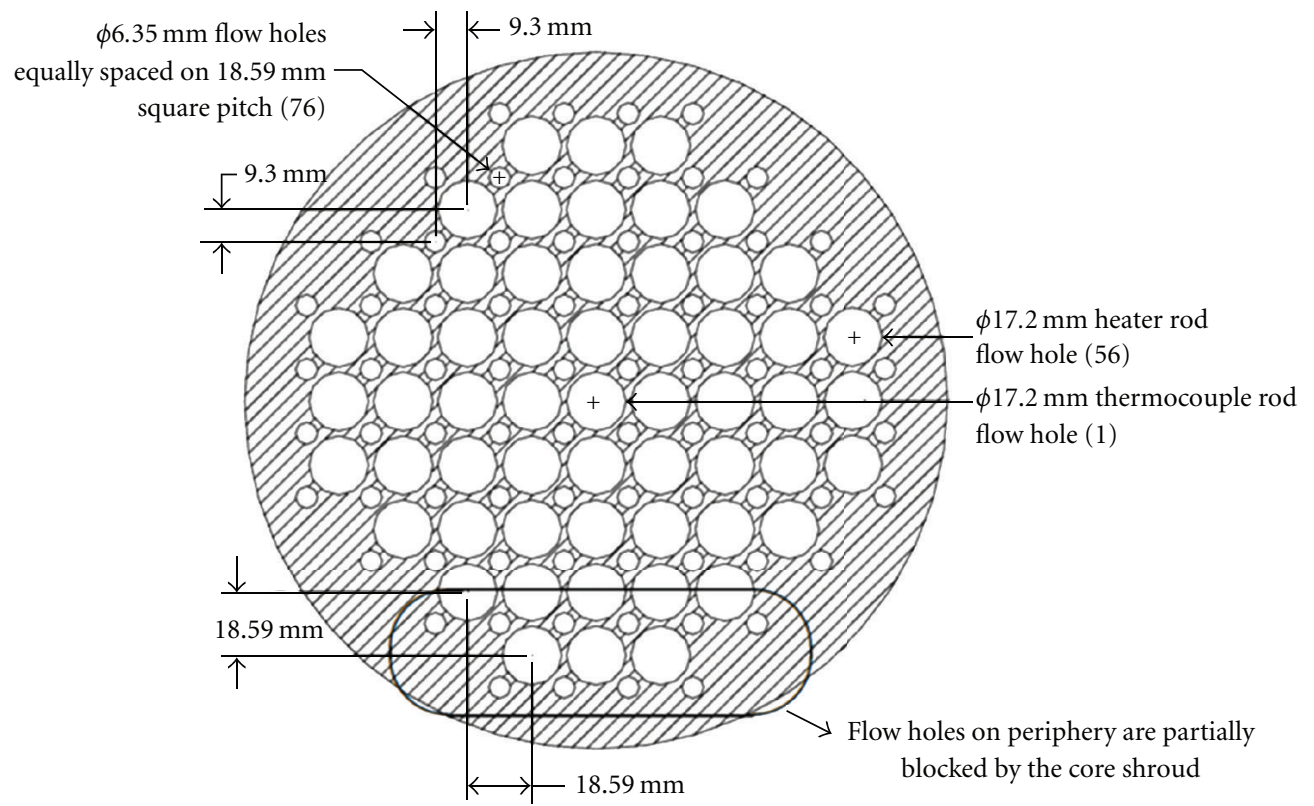

Figure 4: Lower core flow plate layout [12]. See Figure 5 for flow blockage detail.

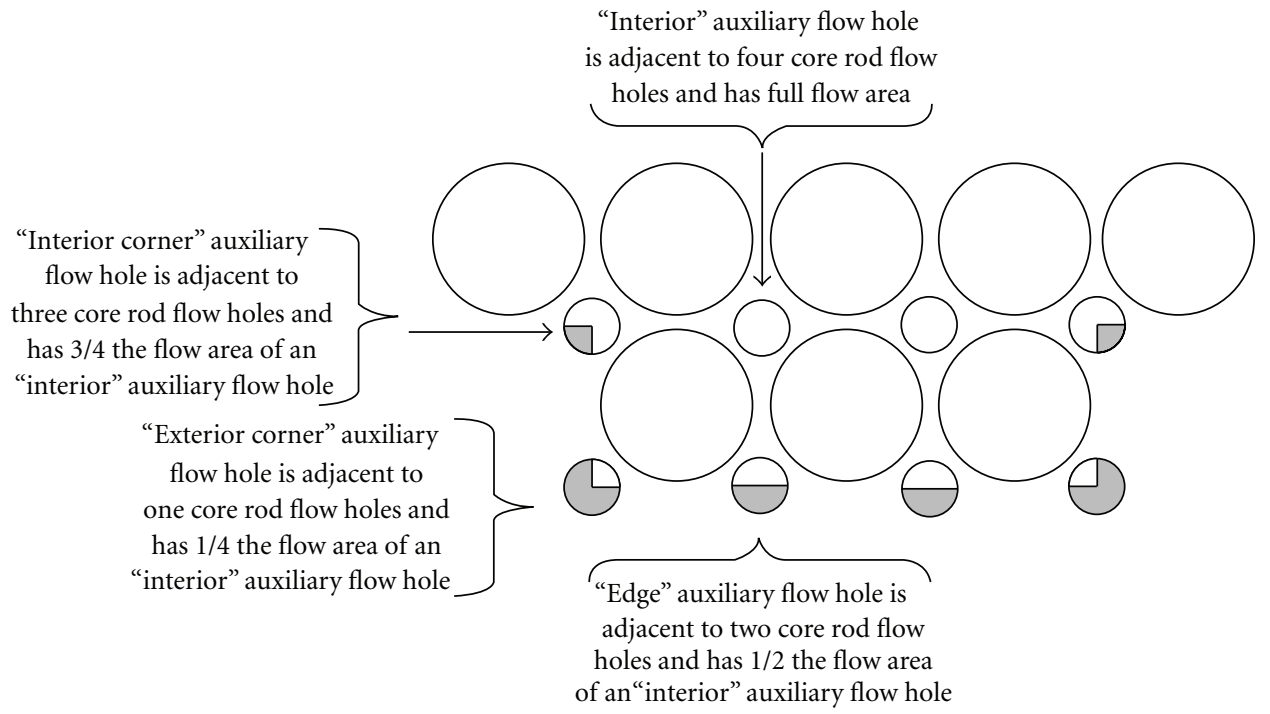

FIgURE 5: Auxiliary flow hole blockage by core shroud [12].

riser, the upper plenum (UP), the PRZ, the SG primary side, the cold leg (CL) downcomer, and the lower plenum (LP).

The core is modelled with 56 cylindrical heater rods. A lower core flow plate is located at the core entrance and is shown in Figure 4. The core is shrouded to ensure all flow enters the core via the bottom and travels the entire heated length and to separate the downcomer region from the core region. The core shroud is shaped to partially block the primary coolant flow through the outermost auxiliary flow holes in order to ensure that each heated rod receives approximately equal axial coolant flow, as shown in Figure 5. The amount of blockage is dependent on the number and location of heated rods adjacent to each auxiliary flow hole. The shaded area, Figure 5, indicates where core shroud blocks flow through auxiliary flow holes. A core grid wire, located at core midelevation, is considered in order to maintain the radial alignment of the core rods, Figure 6.

The HL riser, Figure 3, consists of a lower region, an upper region, and a cone transition region. The UP is separated from the heated upper PRZ section by a thick baffle plate having eight holes, spaced uniformly around the baffle plate periphery, which allow free communication of the PRZ to the remainder of the RPV during normal operation and for volume surges into and/or out of the PRZ due to transients. The PRZ is integrated in the RPV and is located in its upper part. In the PRZ are located heater elements, which are modulated 


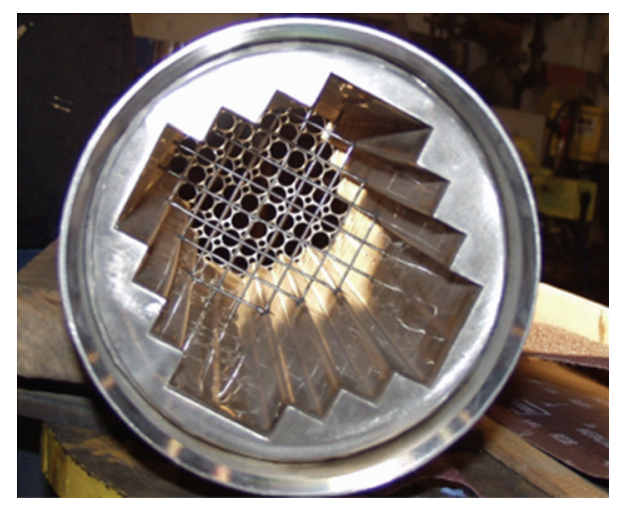

Figure 6: Photo of core shroud showing lower core flow plate behind the core grid wires [12].

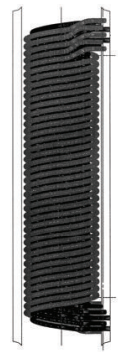

Elevation $\left(180^{\circ}\right)$

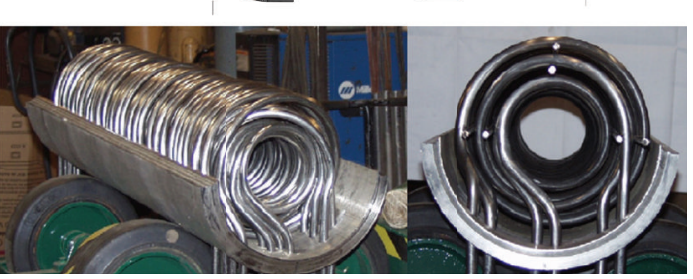

Figure 7: Helical coil SG bundle [13, 20].

by the test facility control system to maintain nominal primary system pressure at the desired value. The CL downcomer region is an annular region bounded by the RPV wall on the outside and the HL riser on the inside, and the flow area reduces at the HL riser cone. In the SG primary side section is inserted the SG helical coil bundle, Figure 7. The entire RPV is covered by Thermo-12 hydrous calcium silicate insulation.

3.3. OSU-MASLWR Secondary Side Overview. The secondary circuit $[1,2,8-13]$ includes the FW treatment and storage system, the main FW pump (MFP), the main FW (MFW) system supply lines, the SG secondary side internal to the vessel, the main steam (MS) system, and associated FW and steam valves.

Potable water, coming from the city water supply, passes through a mechanical filter and a resin bed to remove impurities and flows to the FW storage tank. The MFW system supplies deionized and demineralized water to the SG. The MFP is a positive displacement pump and can be isolated from the downstream main FW system supply lines by pneumatic motor operated globe valve MF-508 (FW supply valve). The MFP controller is interlocked with the MFP discharge isolation valve MF-508 position, to ensure that the MFP is not energized unless MF-508 is fully open. The single MFW line splits into three supply lines, one for each coil bank of SG tubes.

The SG of the facility is a once through heat exchanger and is located within the RPV in the annular space between the HL riser and the inside surface of the RPV. The tube bundle, Figure 7, is a helical coil consisting of fourteen tubes. There are three separate parallel coils of stainless steel tubes. The outer and middle coils consist of five tubes each while the inner coil consists of four tubes. Each coil is joined at a common inlet header and each of them exhausts the superheated steam into a common steam drum from where it is subsequently exhausted to atmosphere via the MS system. The FW enters at the bottom of the SG and boils off after travelling a certain length in the SG. This boil-off length is a function of both core power and MFW flow rate. Nominally, the boil-off length is approximately $40 \%$ shorter than the actual length of the SG tubes so the steam will leave the SG superheated. The value of the degree of the steam superheat is changed in order to control the facility.

The steam received in the SG steam drum goes to the MS line, Figure 8, and that exhausts the SG superheated steam to atmosphere. A pneumatic motor operated globe valve MS502 (MS header drain line isolation valve) is immediately downstream of the SG steam drum. Another motor operated globe valve, MS-503 (MS header isolation valve), isolates the MS header from the steam header drain line. In order to have always an open discharge for the SG, the MS-502 and MS-503 are interlocked to prevent them both from being simultaneously commanded shut.

\subsection{OSU-MASLWR Containment Structures Overview.} The OSU-MASLWR containment structures [1, 2, 8-13], Figure 9, consist of two vessels, a high-pressure containment vessel (HPC) and a cooling pool vessel (CPV), with a heat transfer surface between them to establish the proper heat transfer area. The HPC simulates the containment structure in which the MASLWR RPV sit and the CPV simulates the cavity within which the MASLWR containment structure is located.

The HPC consists of a lower cylindrical section, an eccentric cone section, an upper cylindrical section, and a hemispherical upper-end head. The entire HPC is covered by Thermo-12 hydrous calcium silicate insulation.

The CPV consists of a right cylindrical tank covered by Thermo-12 hydrous calcium silicate insulation. One disk rupture connects the HPC and the CPV.

The heat transfer plate, having the same height of the HPC without the hemispherical head, provides the heat conduction between the HPC and CPV. The heat transfer plate is scaled in order to model the heat transfer area between the MASLWR design high-pressure containment vessel and the cooling pool in which it sits.

For scaling reasons, in order to have an adiabatic boundary condition in all the wall of the HPC except through the heat transfer plate wall, where the condensation has to take place, containment heaters have been installed permitting the 


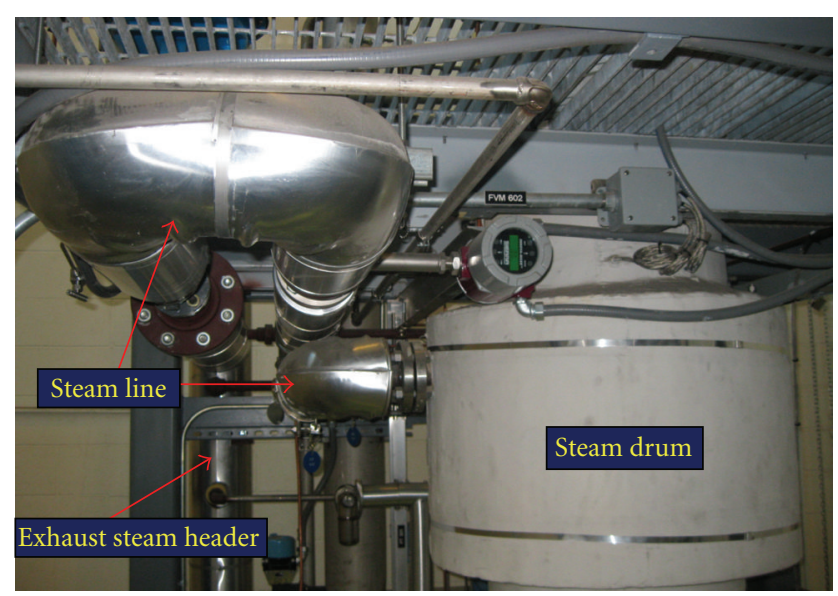

FIGURE 8: Main steam line photo.

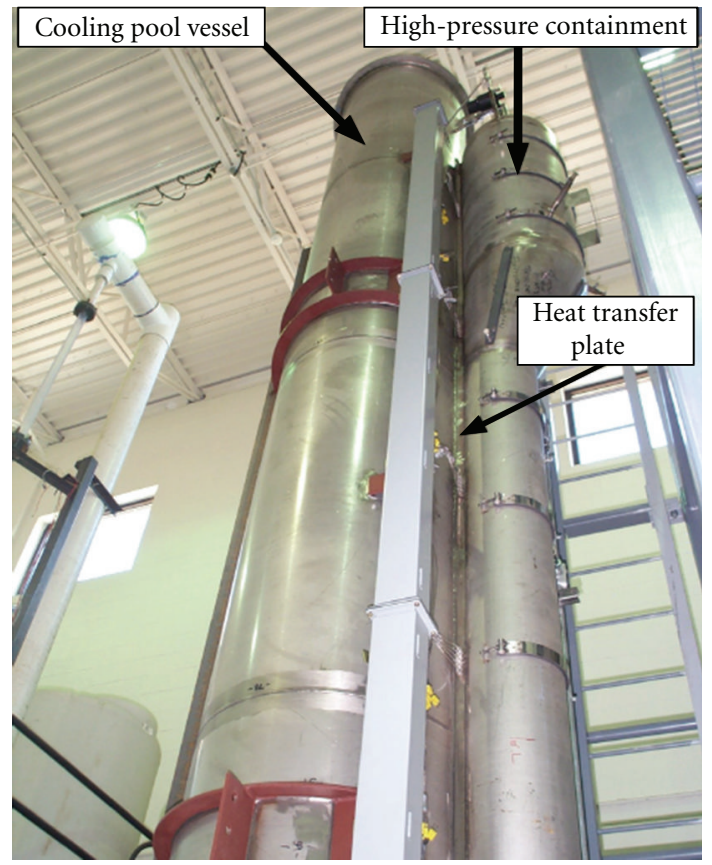

FIGURE 9: OSU-MASLWR containment structures photo $[1,2,11]$.

heat transfer takes place only between the CPV and HPC containment. These heaters are located in the exterior surface of the HPC, under the insulation, and above the containment water level.

3.5. OSU-MASLWR ADS Lines Overview. The two middle ADS lines, two high ADS lines, and the two ADS sump recirculation lines are modelled separately [1, 2, 8-13]. Figure 10 shows the schematic diagram of the OSU-MASLWR RPV, ADS lines, and containment structures.

The ADS sump recirculation lines are horizontally oriented and connect the RPV lower CL to the HPC. A pneumatic motor operated globe valve is located in each line. Downstream from each isolation valve is a transition piece with an internal square-edge orifice. These two lines enter the HPC, penetrate it, and then turn downward before terminating below the HPC waterline. No sparger is considered for these lines.
The middle ADS lines are horizontally oriented and connect the RPV CL to the HPC. A pneumatic motor-operated globe valve is located in each line. Downstream from each isolation valve is a transition piece with an internal squareedge orifice. These two lines enter the HPC, penetrate it, and then turn downward before terminating below the HPC waterline. A sparger is considered at the end of this line.

The high ADS lines are horizontally oriented and connect the RPV PRZ steam space with the HPC. A pneumatic motor operated globe valve is located in each line. Downstream from each isolation valve is a transition piece with an internal square-edge orifice. The two ADS vent lines enter the HPC above the waterline, penetrate it, and then terminate with a sparger.

3.6. OSU-MASLWR Data Acquisition and Control Subsystem Overview. The data acquisition and control system $[1,2,8$ 13] consist of various field input/output modules, a programmable logic controller module, and a desktop computer. The data acquisition and control subsystem process input signals from system components, generate control signals as determined by the control logic, and apply those control signals to applicable system components. The operator can monitor parameters and alarms in the main control screen, via a graphical user interface as it is shown in Figure 11.

Individual system component operation algorithms are considered in the facility. The PRZ heaters, for examples, can be operated manually or in automatic mode. In automatic mode, in order to control the primary pressure, the operator fixes the primary pressure set point and the control system, by using a proportional integral differential methods, and adjusts the heater controller electrical output. The core heaters, for example, can be operated in manual mode, constant power mode, or decay mode. In decay mode the core power follows a user specify curve.

\section{OSU-MASLWR Testing Program}

The first tests conducted in the OSU-MASLWR facility [813] were in support of the MASLWR concept design verification. Table 2 shows, in chronological order, the type of test already conducted in the facility. During this test program, the MASLWR normal startup, the operation, and its shutdown are thermal hydraulically demonstrated.

4.1. OSU-MASLWR-001 Description. The purpose of the test OSU-MASLWR-001 [1, 8-13], a design basis accident for MASLWR concept design, is to determine the behavior of the RPV and containment pressure following an "inadvertent actuation of one middle ADS valve" located below the HPC and RPV water level. The test successfully demonstrated the thermal hydraulic behavior of the MASLWR design during the transient sequence following this design basis event.

Following the inadvertent middle ADS actuation, the blowdown of the primary system takes place. A subcooled blowdown characterized by a fast RPV depressurization takes place after the start of the transient (SOT). A two-phase blowdown occurs when the differential pressure, at the break 


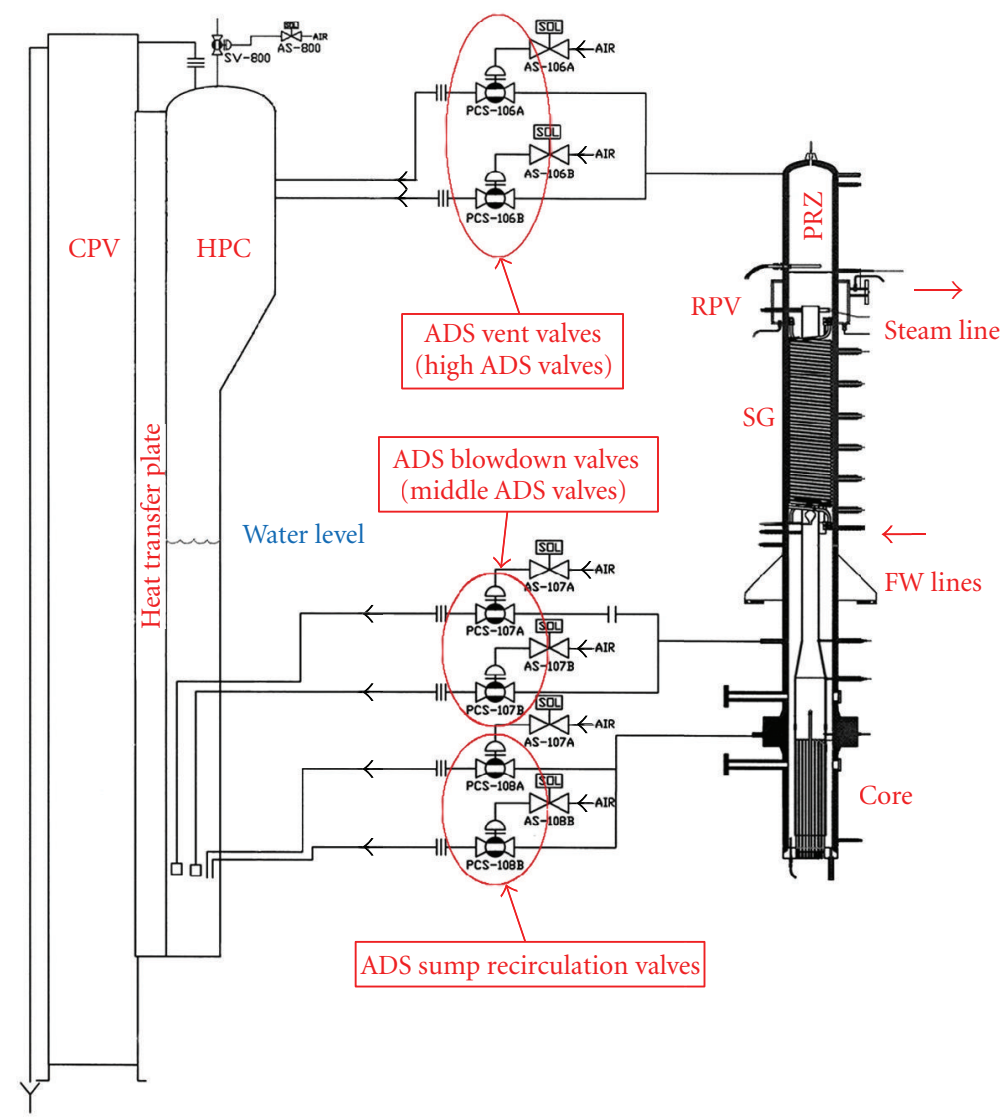

Figure 10: Schematic diagram of the OSU-MASLWR RPV, ADS lines, and containment structures $[2,20]$.

TABLE 2: Summary of the previous OSU-MASLWR testing program $[8,11,13]$.

\begin{tabular}{|c|c|c|c|c|c|c|c|}
\hline \multirow[b]{2}{*}{ Name of the test } & \multirow[b]{2}{*}{ Type of test } & \multicolumn{6}{|c|}{ ADS line configuration } \\
\hline & & $\begin{array}{l}\text { Middle } \\
\text { ADS } 1 \\
(\%) \\
\end{array}$ & $\begin{array}{l}\text { Middle } \\
\text { ADS2 } \\
(\%) \\
\end{array}$ & $\begin{array}{l}\text { High } \\
\text { ADS } 1 \\
(\%) \\
\end{array}$ & $\begin{array}{l}\text { High } \\
\text { ADS2 } \\
(\%)\end{array}$ & $\begin{array}{l}\text { Sump } \\
\text { Recirc } 1 \\
(\%)\end{array}$ & $\begin{array}{l}\text { Sump } \\
\text { Recirc } 2 \\
(\%) \\
\end{array}$ \\
\hline OSU-MASLWR-001 & $\begin{array}{l}\text { Inadvertent actuation of } 1 \\
\text { submerged ADS valve. }\end{array}$ & $\begin{array}{c}\text { Failed } \\
\text { Shut }\end{array}$ & 100 & 100 & 100 & 100 & 100 \\
\hline OSU-MASLWR-002 & $\begin{array}{l}\text { Natural circulation at core } \\
\text { power up to } 210 \mathrm{~kW} \text {. }\end{array}$ & N/A & N/A & N/A & N/A & N/A & N/A \\
\hline OSU-MASLWR-003A & $\begin{array}{l}\text { Natural circulation at core } \\
\text { power of } 210 \mathrm{~kW} \text {. } \\
\text { (Continuation of test } 002 \text {, } \\
\text { establishing the initial } \\
\text { conditions for the } 003 \mathrm{~B} \\
\text { test.) }\end{array}$ & $\begin{array}{l}\text { Failed } \\
\text { Shut }\end{array}$ & N/A & N/A & N/A & N/A & N/A \\
\hline OSU-MASLWR-003B & $\begin{array}{l}\text { Inadvertent actuation of } 1 \\
\text { high-containment ADS } \\
\text { valve }\end{array}$ & $\begin{array}{c}\text { Failed } \\
\text { Shut }\end{array}$ & 100 & $\begin{array}{l}\text { Failed } \\
\text { Shut }\end{array}$ & 100 & 100 & 100 \\
\hline
\end{tabular}

location, results in fluid flashing. A choked two-phase flow condition prevails, and a decrease in depressurization rate of the primary system is experimentally observed. When the PRZ pressure reaches saturation, single-phase blowdown occurs, and the depressurization rate increases. The primary and HPC pressure are shown in Figure 12.

At 539 s after the SOT, the pressure difference between the RPV and the HPC reaches a value less than $0.517 \mathrm{MPa}$, one of the high ADS valve is opened and, with approximately $10 \mathrm{~s}$ of delay, the other high ADS valve is opened equalizing the pressure of the primary and HPC system.

At $561 \mathrm{~s}$ after the SOT, the pressure difference between the RPV and the HPC reaches a value less than $0.034 \mathrm{MPa}$, one sump recirculation valve is opened, and, with approximately $10 \mathrm{~s}$ of delay, the other sump recirculation valve is opened terminating the blow-down period and starting the refill 


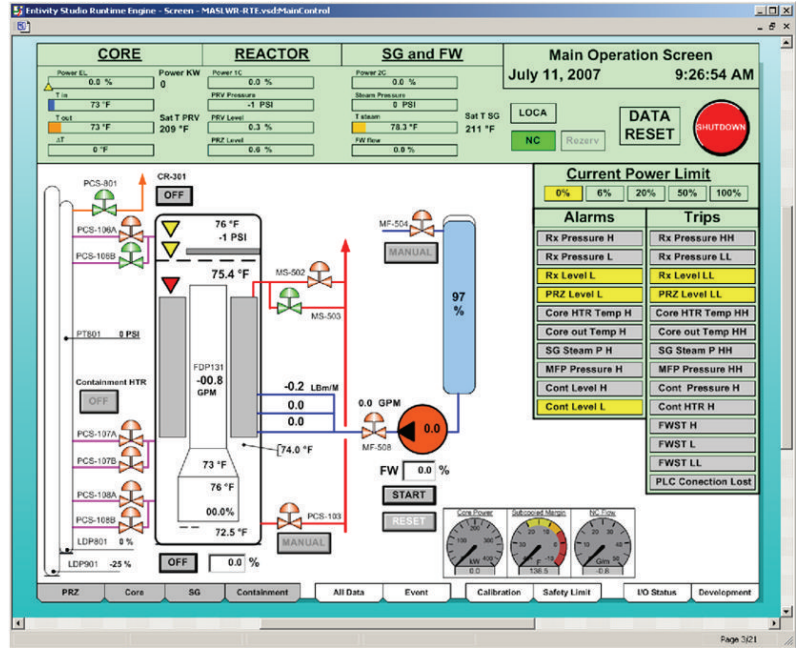

Figure 11: Data acquisition and control system main control screen [12].

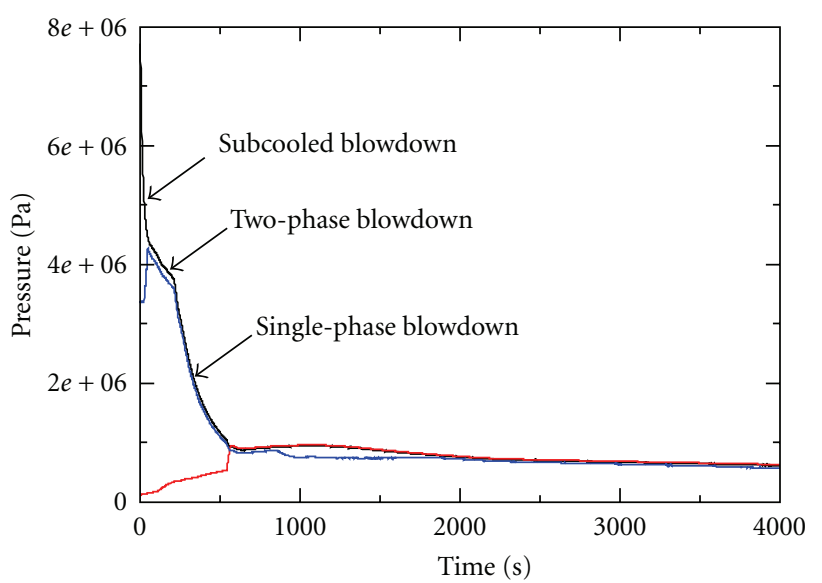

\begin{tabular}{ll}
- & RPV_P_001 \\
- & HPC_P_001 \\
\hline & Psat_001
\end{tabular}

FIGURE 12: RPV and HPC pressure behaviour during the OSUMASLWR-001 test (the Psat, saturation pressure, is based on the temperature at the core outlet) $[8,11]$.

period. The refill period takes place for the higher relative coolant height in the HPC compared to the RPV. Figure 13 shows the RPV level evolution experimentally detected during the test. The RPV level water never fell below the top of the core during the execution of the test 1 . Figure 14 shows the HPC level during the test.

During the saturated blowdown period, the inlet and the outlet temperature of the core are equal to each other assuming the saturation temperature value. A core reverse flow and a core coolant boiling off at saturation are present in the facility during this period. When the refill takes place, the core flow normal flow direction is restarted and a delta $\mathrm{T}$ core is observed depending on the refill rate and core power, Figure 15.

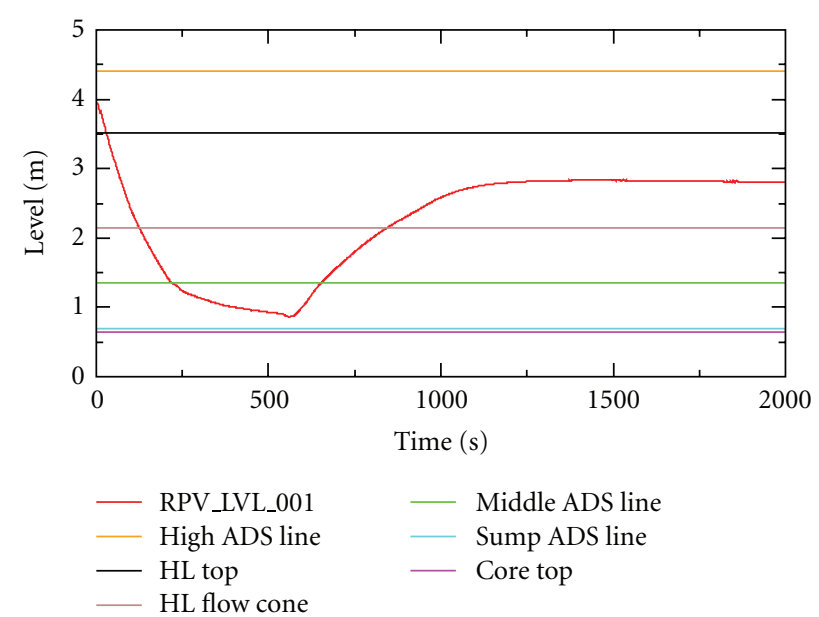

FIGURE 13: RPV water level inventory behaviour during the OSUMASLWR-001 test $[8,11]$.

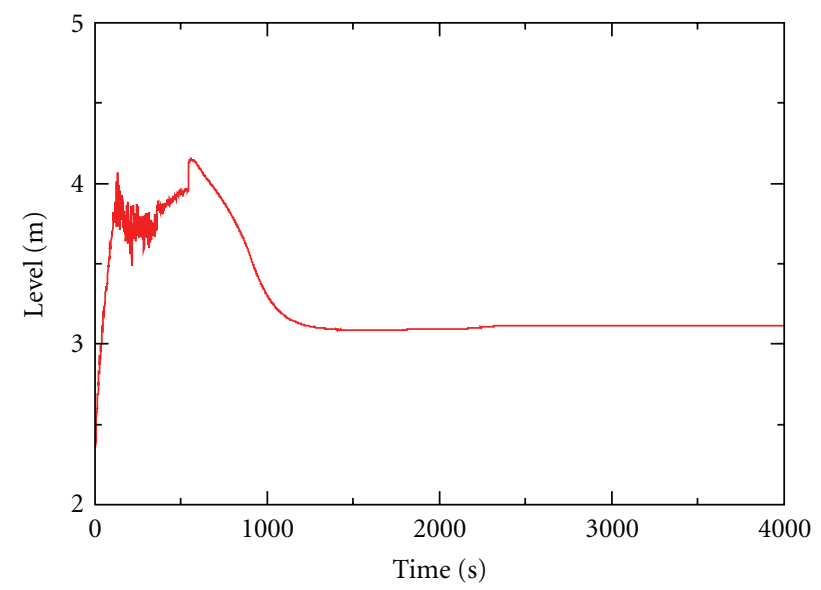

— HPC_LVL_001

FIgure 14: HPC level behaviour during the OSU-MASLWR-001 test $[21,22]$.

When the refill of the reactor takes place, the level of the coolant reaches the location of the flow rate HL measurement point; therefore an increase of the RPV flow rate is detected for this phenomenon, Figure 16.

4.2. OSU-MASLWR-002 and 003A Description. The test OSU-MASLWR-002 and OSU-MASLWR-003A [1, 8-13] investigated the primary system flow rates and secondary side steam superheat for a variety of core power levels and FW flow rate. Table 3 shows the OSU-MASLWR-002 and OSUMASLWR-003A test conditions.

The OSU-MASLWR-002 stepped power level incrementally up to $165 \mathrm{~kW}$, varying FW flow rate at each power level. Since the $210 \mathrm{~kW}$ data in OSU-MASLWR-002 was not used, because of liquid carryover in the SG, the OSU-MASLWR$003 \mathrm{~A}$ was an extended $210 \mathrm{~kW}$ steady test establishing initial conditions for the following test OSU-MASLWR-003B. 
TABLE 3: OSU-MASLWR-002 and OSU-MASLWR-003A test conditions $[8,11,12]$.

\begin{tabular}{|c|c|c|c|c|c|c|c|c|c|c|c|}
\hline \multirow{2}{*}{ Test } & \multirow[b]{2}{*}{$\begin{array}{c}\text { Start time } \\
(\mathrm{s})\end{array}$} & \multirow[b]{2}{*}{$\begin{array}{l}\text { End time } \\
(\mathrm{s})\end{array}$} & \multicolumn{5}{|c|}{ Primary } & \multicolumn{4}{|c|}{ Secondary } \\
\hline & & & $\begin{array}{c}\text { Core power } \\
(\mathrm{kW})\end{array}$ & $\begin{array}{l}\mathrm{T} \text { in } \\
(\mathrm{K})\end{array}$ & $\begin{array}{l}\text { T_out } \\
(\mathrm{K})\end{array}$ & $\begin{array}{c}\text { Flow } \\
(\mathrm{L} / \mathrm{min})\end{array}$ & $\begin{array}{l}\mathrm{Vel} \\
(\mathrm{m} / \mathrm{s})\end{array}$ & $\begin{array}{l}\text { T_in } \\
(\mathrm{K})\end{array}$ & $\begin{array}{c}\text { T_out } \\
(\mathrm{K})\end{array}$ & $\begin{array}{c}\mathrm{P} \\
(\mathrm{MPa})\end{array}$ & $\begin{array}{c}\text { Feedwater } \\
(\mathrm{kg} / \mathrm{min})\end{array}$ \\
\hline \multirow{8}{*}{002} & 0 & 127 & 80.0 & 489 & 506 & 65.6 & 0.13 & 292 & 482 & 1.41 & 1.13 \\
\hline & 250 & 550 & 100.0 & 491 & 509 & 77.9 & 0.16 & 292 & 488 & 1.40 & 1.81 \\
\hline & 750 & 1200 & 100.0 & 490 & 508 & 80.0 & 0.16 & 292 & 494 & 1.38 & 2.14 \\
\hline & 1380 & 1570 & 100.0 & 486 & 505 & 81.9 & 0.17 & 292 & 494 & 1.37 & 2.50 \\
\hline & 1670 & 1920 & 110.0 & 483 & 503 & 84.9 & 0.17 & 292 & 493 & 1.36 & 2.49 \\
\hline & 2060 & 2250 & 125.0 & 482 & 503 & 88.5 & 0.18 & 292 & 493 & 1.35 & 2.50 \\
\hline & 2450 & 2600 & 160.0 & 481 & 505 & 104.1 & 0.21 & 292 & 488 & 1.36 & 3.85 \\
\hline & 2700 & 2930 & 165.0 & 478 & 503 & 105.0 & 0.21 & 293 & 482 & 1.35 & 3.83 \\
\hline \multirow{2}{*}{ 003A } & 0 & 450 & 210.0 & 501 & 528 & 118 & 0.24 & 293 & 507 & 1.581 & 4.14 \\
\hline & 550 & 1000 & 210.0 & 499 & 526 & 120 & 0.24 & 293 & 509 & 1.567 & 4.56 \\
\hline
\end{tabular}

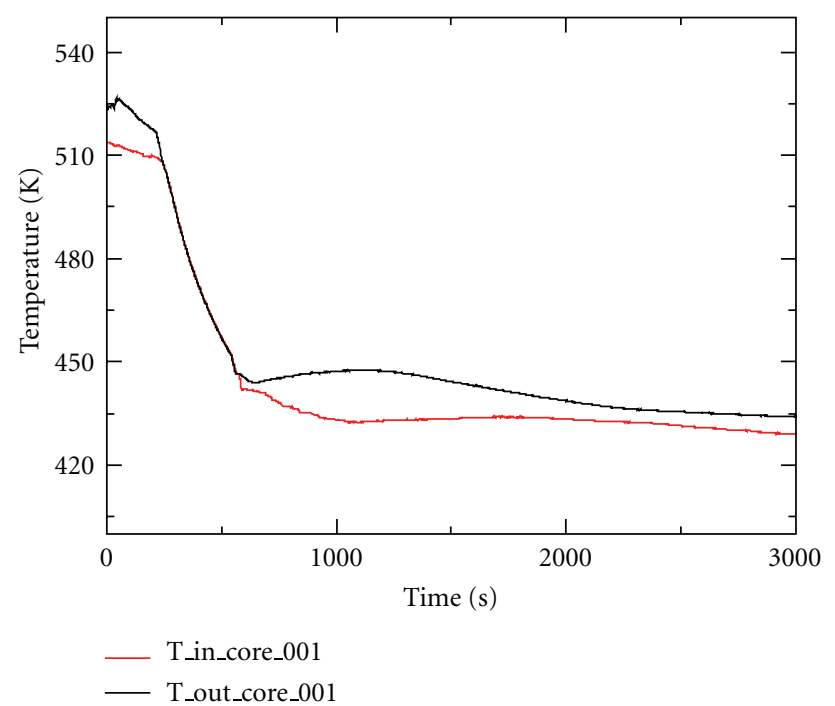

FIGURE 15: Inlet/outlet core temperature behavior during the OSUMASLWR-001 test [8].

During these two tests, seven different core powers were used as well as nine different FW flow rates. Figures 17 and 18 show the inlet, outlet core, and top of the HL temperature behaviour for the OSU-MASLWR-002 and OSU-MASLWR003A test, respectively.

In general the value of the degree of the steam superheat is changed in order to control the facility. Since the slope of the MS superheat curve increases if the value of the core power increases and decreases if the value of the FW flow rate increases, the target of these tests was to acquire primary system flow rate and secondary side steam superheat for different core power and FW flow rate. The difference between the MS saturation temperature and the measured MS temperature is used to estimate the value of the MS superheat. Figures 19 and 20 show the steam superheat data for the test OSU-MASLWR-002 and 003A test, respectively. Figure 21 shows the difference of fluid temperature at the inlet of the core and at the exit of the SG primary side for the OSUMASLWR-002 test. By analyzing the experimental data,

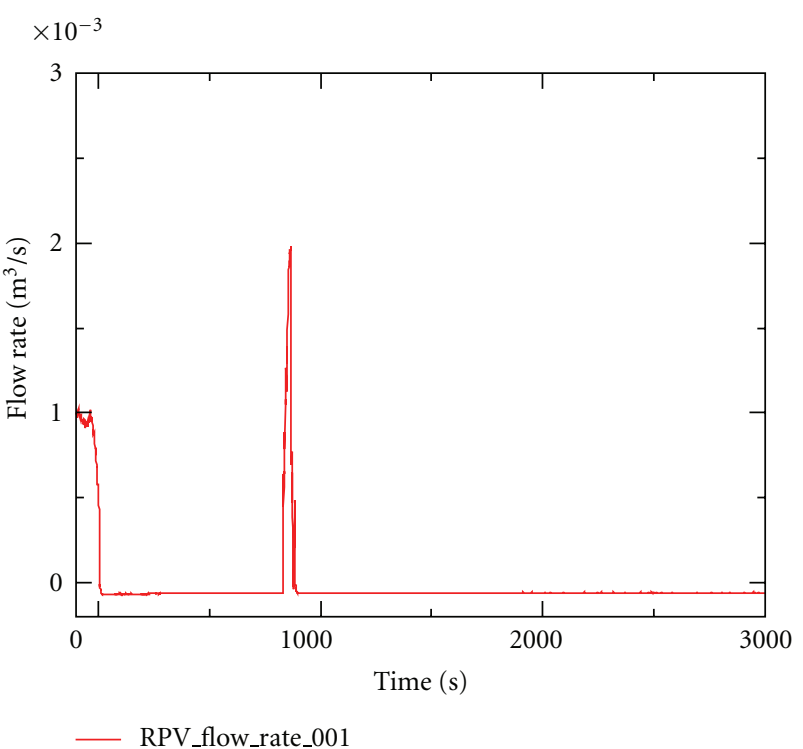

FIGURE 16: RPV flow rate behavior during the OSU-MASLWR-001 test $[8]$.

related to the flow temperature after the SG coils primary side section and the core inlet temperature, it is evident that the direct heat exchange, through the internal shell, between the fluid ascending the HL and the fluid descending the CL, is a crucial parameter for the evaluation of the core inlet temperature and, therefore, the core outlet temperature. In fact, the experimental data show that, along the downcomer region, the fluid increases its temperature between the end of the SG primary side section and the core inlet [13].

4.3. OSU-MASLWR-003B Description. The normal opening sequence used in the MASLWR for the ADS valves is the middle lines first, then the high lines, and finally the sump recirculation lines [8-13]. This sequence minimizes the rise in containment pressure since a large fraction of the energy transferred to the containment is direct into the subcooled containment coolant. However, if the high lines are actuated first, the rise in containment pressure will be larger than 


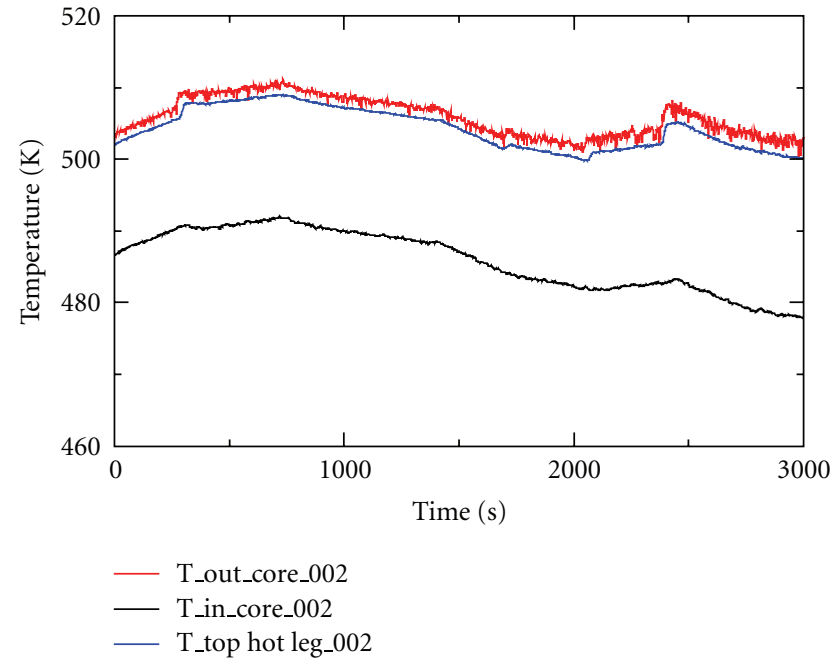

Figure 17: Inlet, outlet core, and top of the hot leg temperature behavior during the OSU-MASLWR-002 test [8].

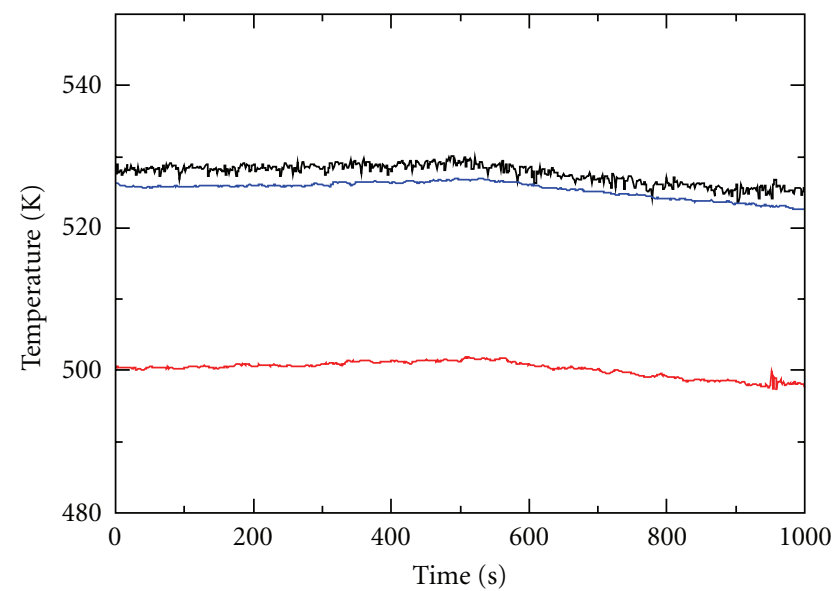

- T_out_core_003A

- T_in_core_003A

- T_top hot leg_003A

FIgURE 18: Inlet, outlet core, and top of the hot leg temperature behavior during the OSU-MASLWR-003A test [8].

the previous one, and, anyway, the chocked flow in the high containment line will limit the rate at which the containment and RPV pressure equalize.

Therefore the purpose of the test OSU-MASLWR-003B is to acquire the pressure transient in the containment and the primary system during the "inadvertent actuation of one high containment ADS valve." This test represents a beyond design basis accident scenario for the MASLWR and thermal hydraulically characterizes the RPV/containment coupling and containment vessel condensation behavior during this kind of transient. During the test, core power is zero and there is not preheating of the containment noncondensation surface areas.

When the high ADS valves open, the pressure equalization of the primary side and containment starts, but it is limited by the chocked flow condition at the ADS nozzles.

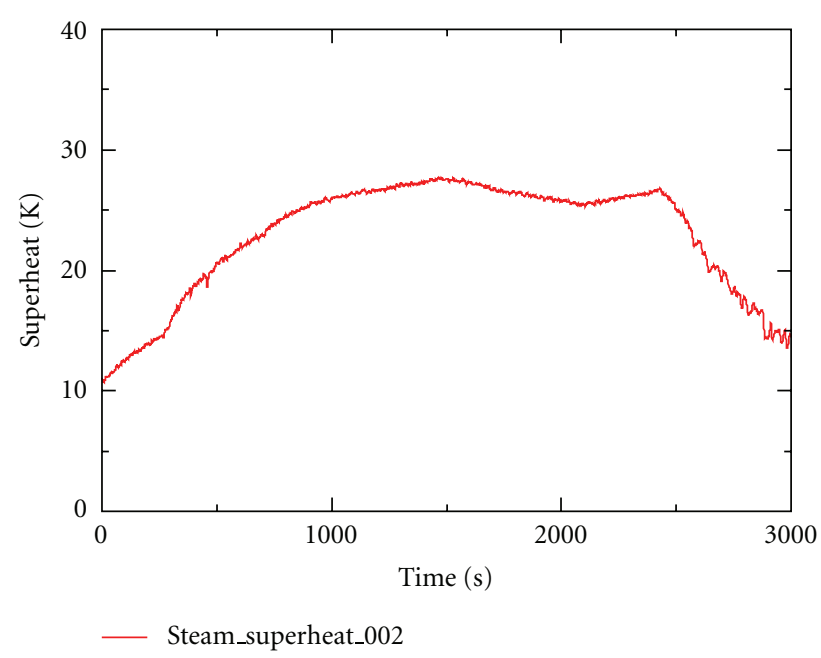

FIGURE 19: Steam superheat behavior during the OSU-MASLWR002 test [11].

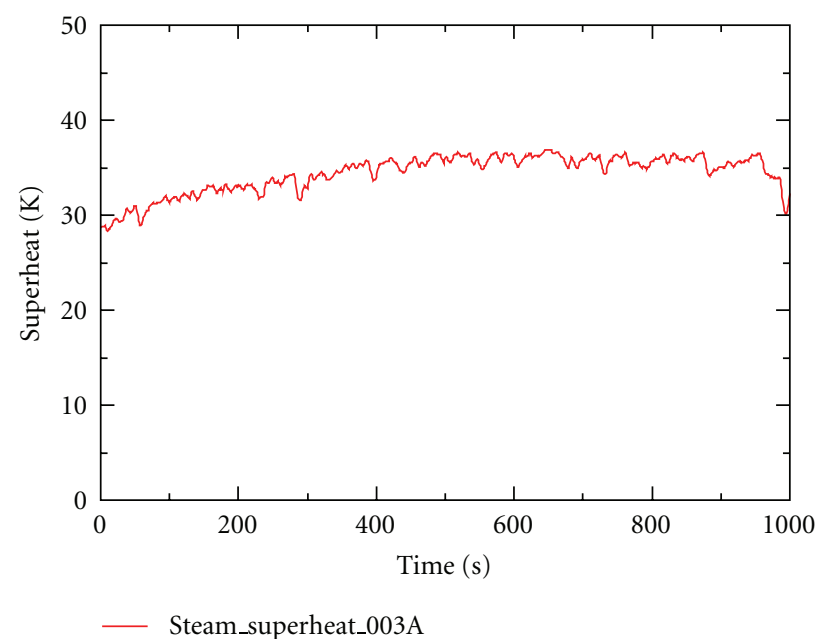

FIgURE 20: Steam superheat behavior during the OSU-MASLWR$003 \mathrm{~A}$ test [11].

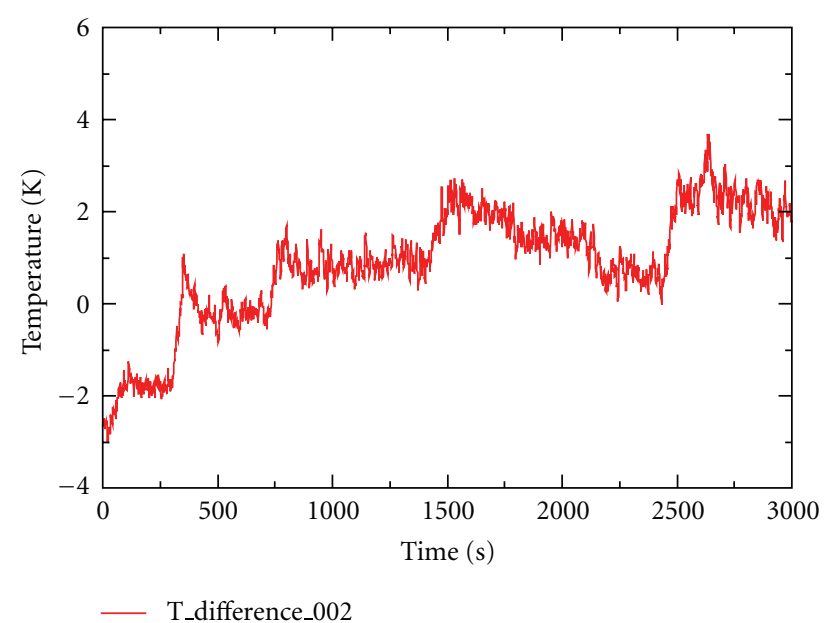

Figure 21: Difference of fluid temperature at the inlet of the core and at the exit of the SG primary side during the OSU-MASLWR002 test $[13,22]$. 


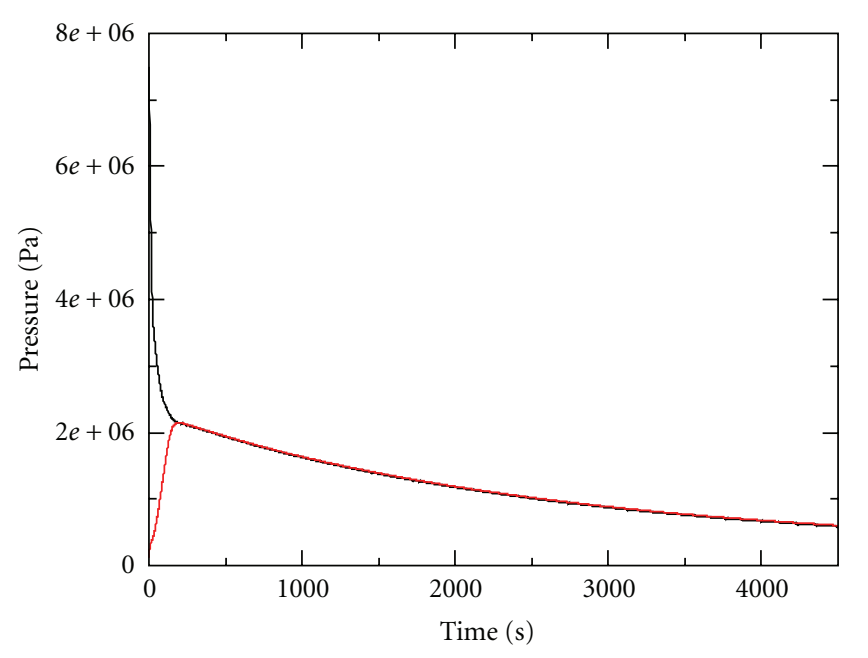

- RPV_P_003B

— HPC_P_003B

FIGURE 22: RPV and HPC pressure behaviour during the OSUMASLWR test $003 \mathrm{~B}[8,11]$.

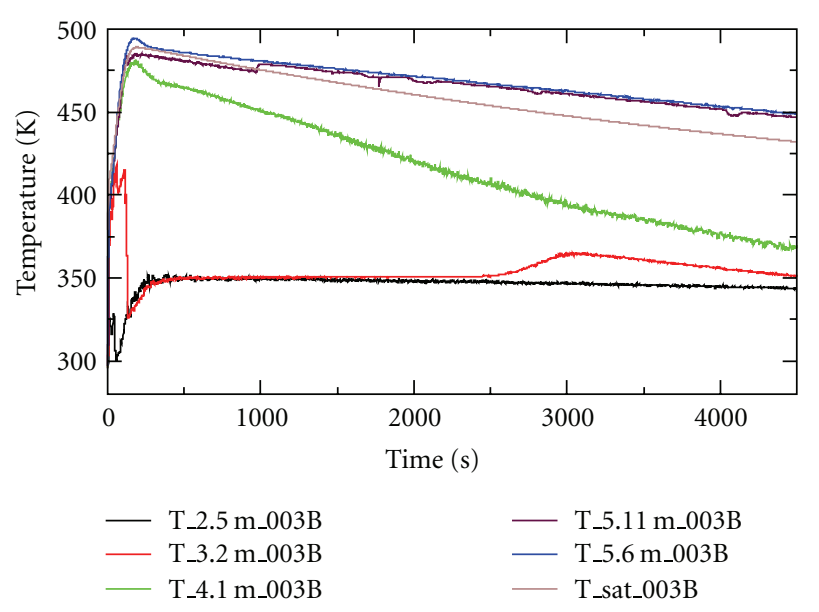

Figure 23: Containment condensation plate wall temperatures behavior during the OSU-MASLWR-003B $[8,11]$.

The upper part of the HPC is filled with the steam, coming from the primary side, where condensing transfers energy to the CPV. The analyses of the experimental data show that the HPC pressure reaches a maximum at 21.15 bar at $185 \mathrm{~s}$ after the SOT. Figure 22 shows the RPV and HPC pressure behaviour.

Since the preheating of the containment noncondensation surface is not considered during the transient, an adiabatic boundary condition in all the wall of the HPC except through the heat transfer plate wall is not maintained; therefore a small distortion at the beginning of the transient is present during the test.

The thermocouples measuring the water temperature located inside the HPC near the heat transfer plate reach quickly the saturation temperature, Figure 23. Since the HPC liquid level reaches about $3.7 \mathrm{~m}$, when the lower thermocouples are submerged, they drop at the liquid temperature,

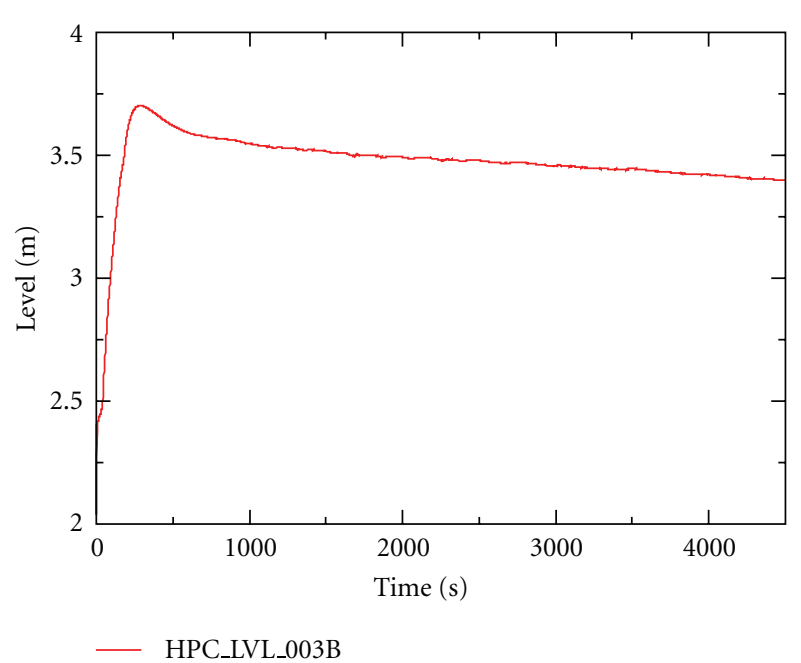

FIgURE 24: HPC liquid level behaviour during the OSU-MASLWR$003 \mathrm{~B}$ test $[8]$.

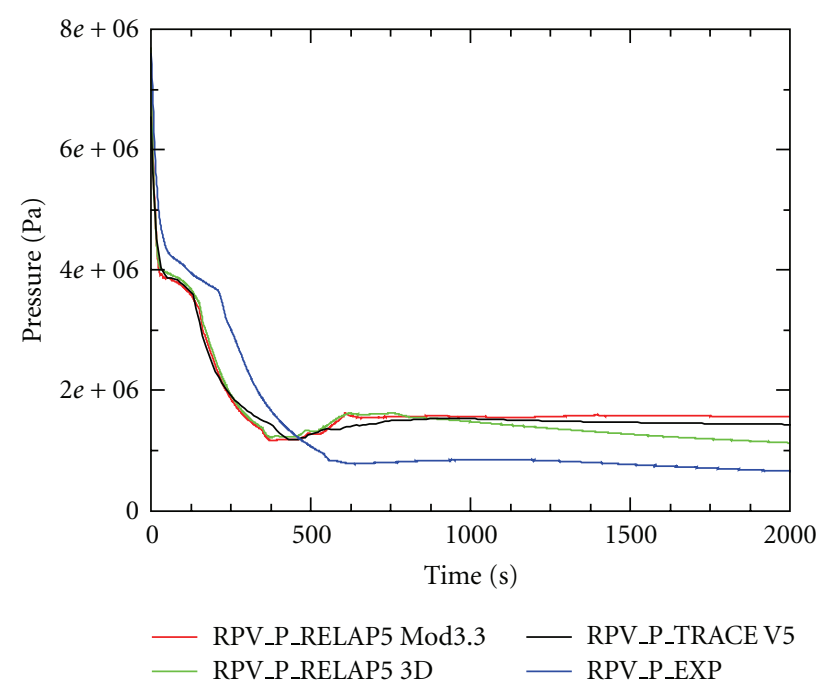

FIgURE 25: Experimental data versus RELAP5/MOD3.3, RELAP5$3 \mathrm{D}$, and TRACE code calculations for primary system pressure behaviour of the OSU-MASLWR-001 test [23].

Figure 24. The RPV level water never fell down the upper part of the core during the execution of the test $003 \mathrm{~B}$.

\section{Code Analyses Performed}

Different computer codes have been developed to characterize two-phase flow systems, from a system and a local point of view [1]. Accurate simulation of transient system behavior of a nuclear power plant or of an experimental test facility is the goal of the best estimate thermal hydraulic system codes. The evaluation of a code's calculation accuracy is accomplished by assessment and validation against appropriate system data developed either from a running system prototype or from a scaled model test facility and characterizes the thermal hydraulic phenomena during both steady-state and transient conditions $[1,2,13,21-23,27,28]$. 


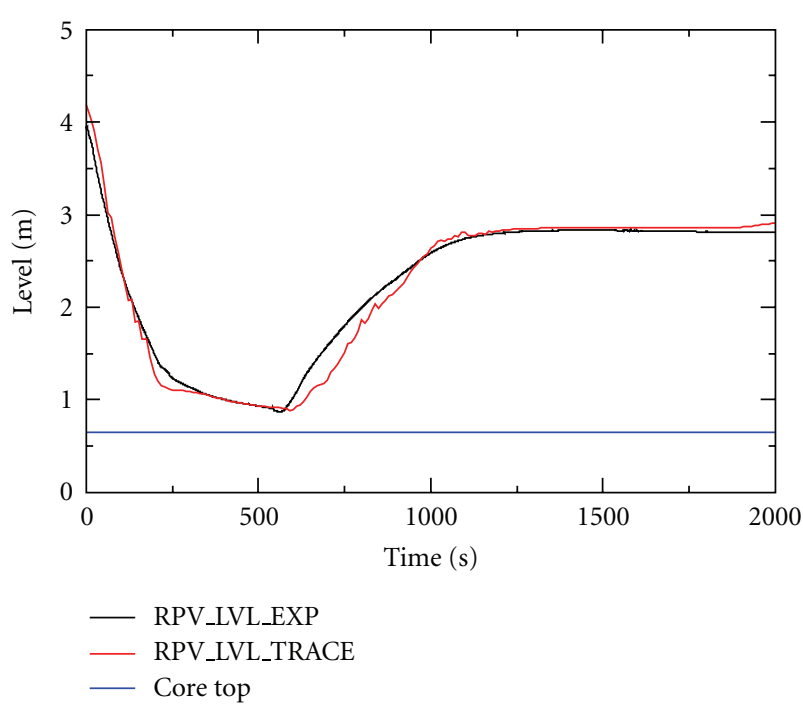

Figure 26: Experimental data versus TRACE V5 patch 02 code calculations for primary system level of the OSU-MASLWR-001 test [1].

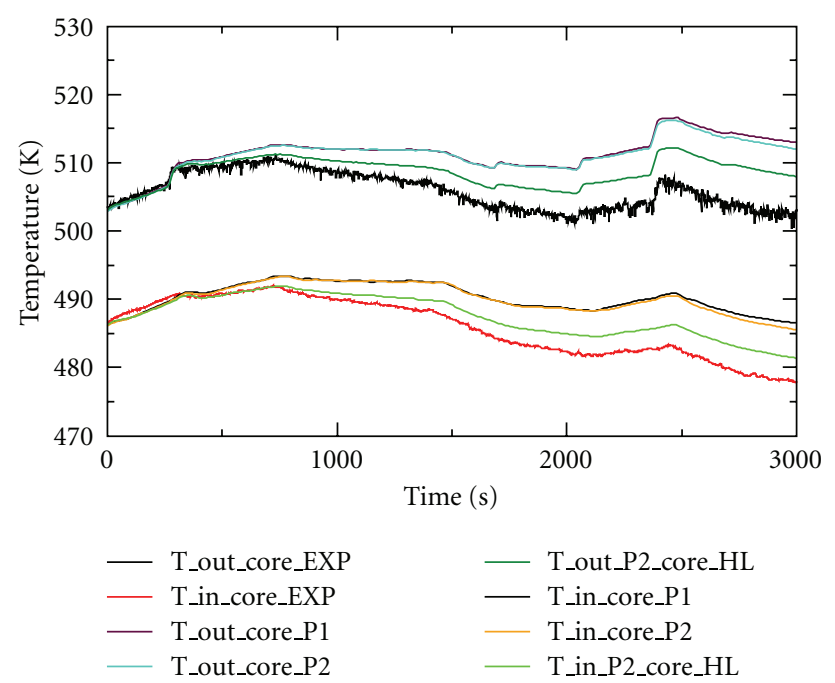

FIgURe 27: Experimental data versus TRACE V5 code calculations for fluid temperature at the core outlet/inlet of the OSU-MASLWR002 test [1] $(\mathrm{P} 1=$ calculation performed with the TRACE V5 patch 01; P2 = calculation performed with the TRACE V5 patch 02; P2_HL calculation performed with the TRACE V5 patch 02 increasing the heat losses of the TRACE model).

In this framework, different analyses have been performed $[1,2,13,21-24,27,28]$, in order to analyze the capability of the best estimate thermal hydraulic system codes to predict the phenomena typical of the MASLWR prototype and their implication to its operation, thermal hydraulically characterized in the OSU-MASLWR test facility. All the previous tests have been analyzed by using different best estimate thermal hydraulic system code. In general the OSUMASLWR test facility nodalizations qualification process is still in progress, considering the facility experimental characterization distributed in the framework of the previously mentioned IAEA ICSP [14-16, 20].

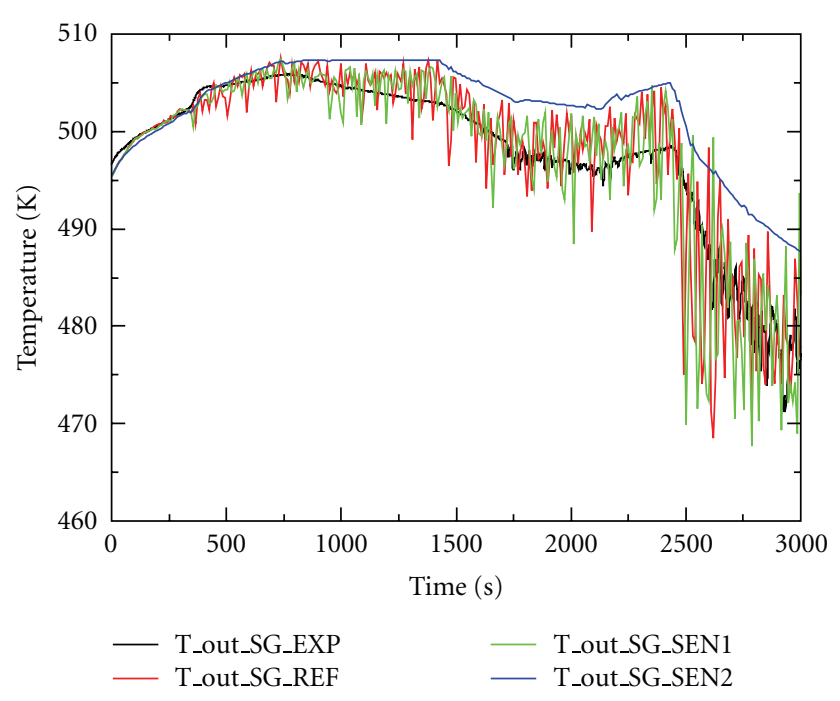

FIgURE 28: Experimental data versus TRACE V5 patch 01 code calculations for the fluid temperature at the SG coil outlet of the OSU-MASLWR-002 test [13]. $(\mathrm{REF}=\mathrm{SG}$ coils modelled with three different "equivalent" oblique group of pipes in order to simulate the three separate parallel coils of tubes; SEN1 = SG coils modelled with three different "equivalent" vertical group of pipes; SEN2 = SG coils modelled with only one "equivalent" vertical group of pipes).

5.1. Code Analyses of the OSU-MASLWR-001 Test. The analysis of the OSU-MASLWR-001 test, performed by using RELAP5/MOD3.3, RELAP5-3D, and TRACE [23], shows that the codes are able to qualitative predict primary/containment coupling phenomena characterizing the test. The subcooled, saturated, and single-phase blowdown is predicted by the codes. The refill of the core, permitting its cooling, is predicted as well. The results of the calculated data show a general overprediction compared with the experimental data. It is thought that this could be due to a combination of selection of vent valve discharge coefficients and condensation models applied to the inside surface of the containment [23]. The pressure behaviour of the RPV predicted by these codes is reported in Figure 25. Different update analyses have been developed by using the TRACE code and reported in [ 1 , $21,22]$. Figure 26 shows the experimental data versus code calculations for primary system level for the OSU-MASLWR001 test predicted by the TRACE code [1]

5.2. Code Analyses of the OSU-MASLWR-002 Test. The analyses of the OSU-MASLWR-002 test, developed by using TRACE $[1,13,21,22,27,28]$, show that the TRACE code is able to qualitatively predict natural circulation phenomena and heat exchange from primary to secondary side by helical SG in superheated condition. An overestimation of the inlet/ outlet core temperature, Figure 27, is predicted by the code. One of the reasons could be an underestimation of the helical coil heat transfer coefficient during the different phases of the transient.

The subcooled, saturated, and superheated regions of the SG secondary side are predicted by the code resulting in steam superheat at the SG exit, Figure 28. Figure 29, developed by using the symbolic nuclear analysis package 

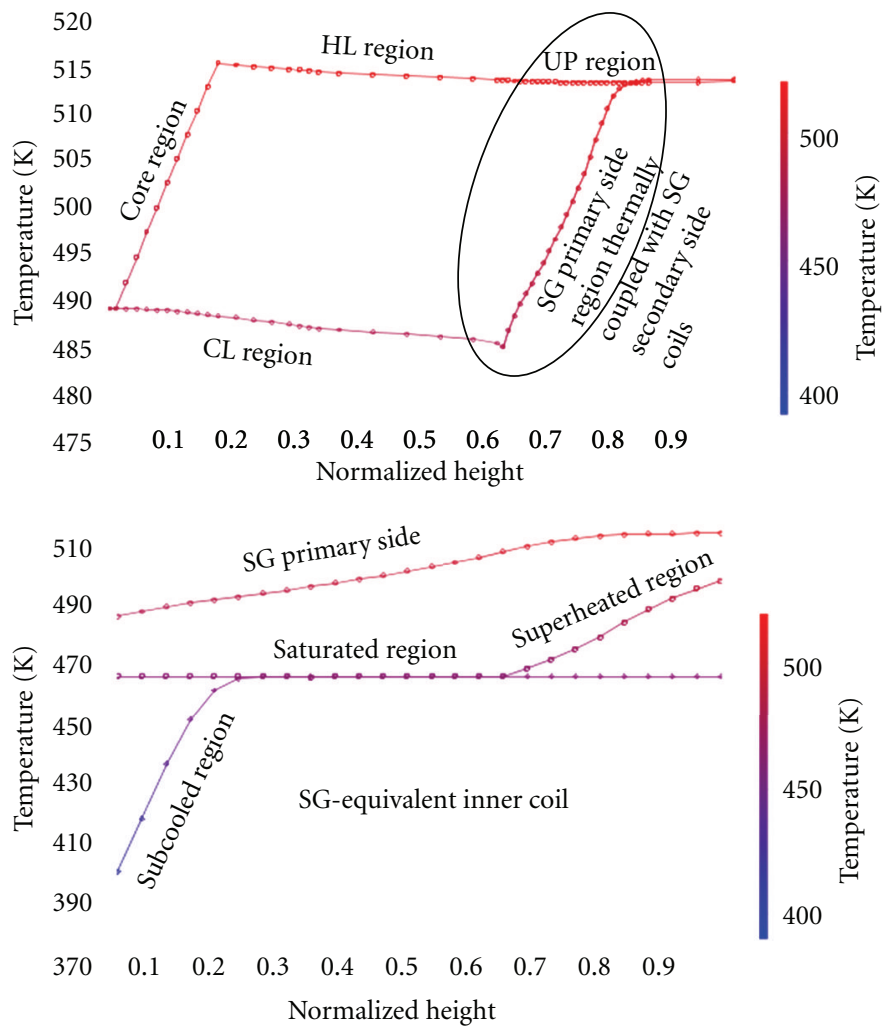

500

450 莺

FIGURE 29: TRACE RPV temperature profile and SG primary side and equivalent inner coil temperature diagram for the OSU-MASLWR-002 test (2605 s after SOT), developed by using SNAP [1].

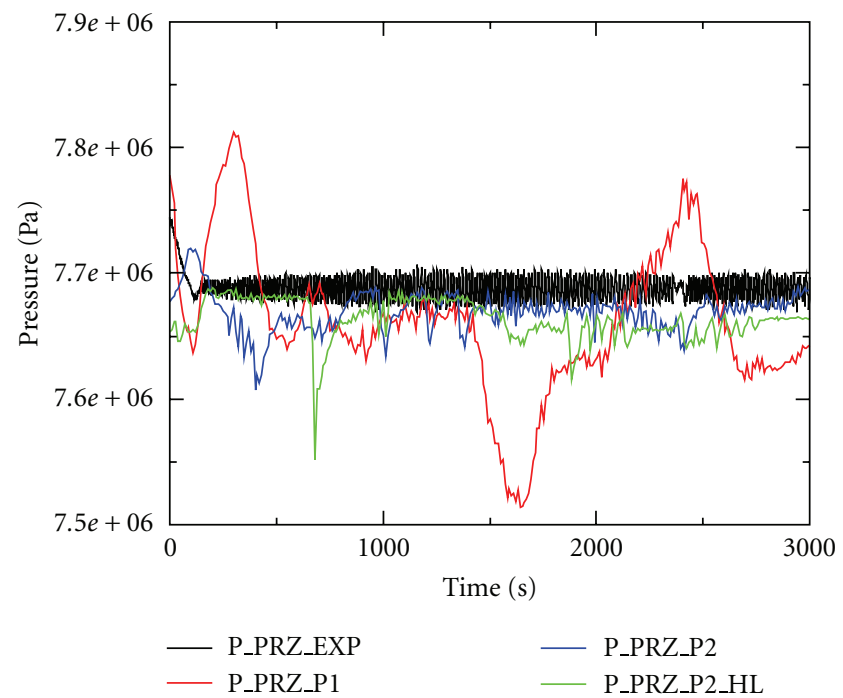

FIGURE 30: Experimental data versus TRACE V5 code calculations for the PRZ pressure of the OSU-MASLWR-002 test [1]. (P1 = calculation performed with the TRACE V5 patch 01; P2 = calculation performed with the TRACE V5 patch 02; P2_HL calculation performed with the TRACE V5 patch 02 increasing the heat losses of the TRACE model).

(SNAP), shows the fluid temperature profile, calculated by TRACE code, along the entire natural circulation loop. A detail of the fluid temperature profile along the inner helical coil cells and the fluid temperature profile along the SG primary side section are shown as well. From this figure, it is possible to identify the subcooled, saturated, and superheat region, of the inner equivalent helical coil. In agreement with the experimental data, the steam will leave the SG superheated.

The analyses of the TRACE calculated data show that one of the reasons of the instability of the superheat condition of the fluid at the outlet of the SG, already observed in [27], is the equivalent SG model used to simulate the different group of helical coils. In particular, if the helical coils are modelled 


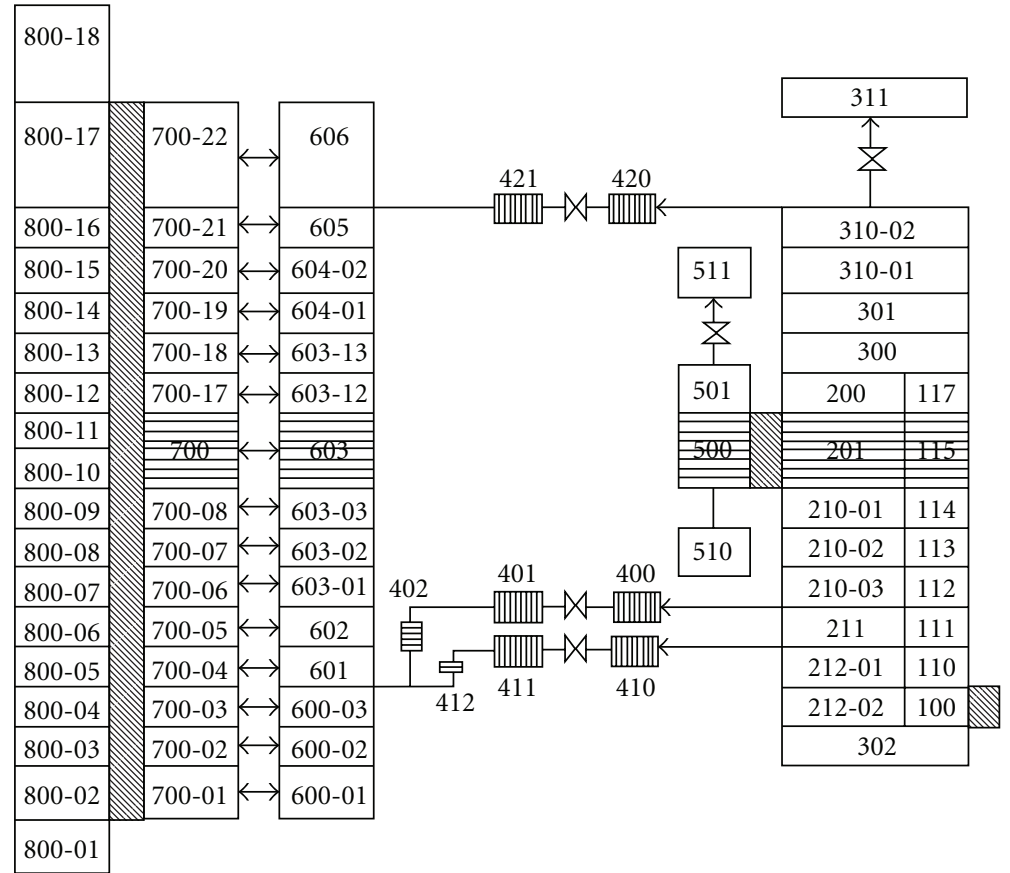

FIGURE 31: RELAP5-3D nodalization [24].

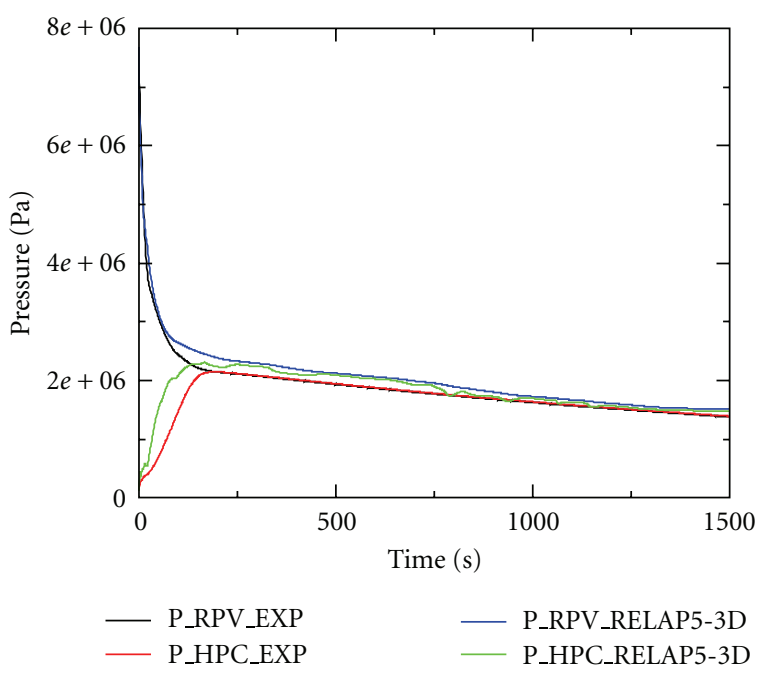

Figure 32: Experimental data versus RELAP5-3D code calculations for the RPV and HPC pressure behaviour of the OSU-MASLWR003B [24].

by only one "equivalent" vertical tube, a more stable fluid temperature at the outlet of the helical tubes is predicted by the code. The model with three different oblique or vertical tubes needs more investigations, in order to study the possible instability conditions predicted by the code [13].

Previous PRZ pressure discrepancies, Figure 30, predicted by the TRACE V5 patch 01 , are now not predicted by the patch 02 that shows, in general, a more stable prediction of PRZ pressure and level [1].

TRACE model heat losses and pressure drop calibration against an experimental characterization is necessary, as it is reported in $[1,13]$, in order to quantitatively evaluate the capability of these codes to simulate the OSU-MASLWR phenomena and therefore use the calculated data for the code assessment. Figure 27 shows the behavior of inlet/outlet core temperature by increasing the heat losses of the TRACE model.

5.3. Code Analyses of the OSU-MASLWR-003 Test. Analyses of the OSU-MASLWR-003 test [24] performed by using the RELAP5-3D code show a general qualitative agreement of the RPV and HPC pressure during the transient. Figure 31 shows the RELAP5-3D nodalization, and Figure 32 shows the RPV and HPC pressure behaviour predicted by the code during its simulations [24].

\section{Activity Related to the OSU-MASLWR Facility}

6.1. Phenomena Simulating Capability of the Facility. The purpose of the OSU-MASLWR test facility is to assess the prototypical MASLWR under normal operation conditions and to assess the passive safety systems under transient conditions. To this end, as said before, four tests were conducted [8-13].

The planned work of OSU, related to the OSU-MASLWR test facility, will be of value not only to specifically investigate the MASLWR concept design further but advance the broad understanding of integral natural circulation reactor plants and accompanying passive safety features as well. Topics of interest for integral reactor plants, which could be investigated in the OSU-MASLWR test facility, are flow stability under normal and transient conditions, the coupled containment-reactor vessel depressurization, and the emergency cooldown. 


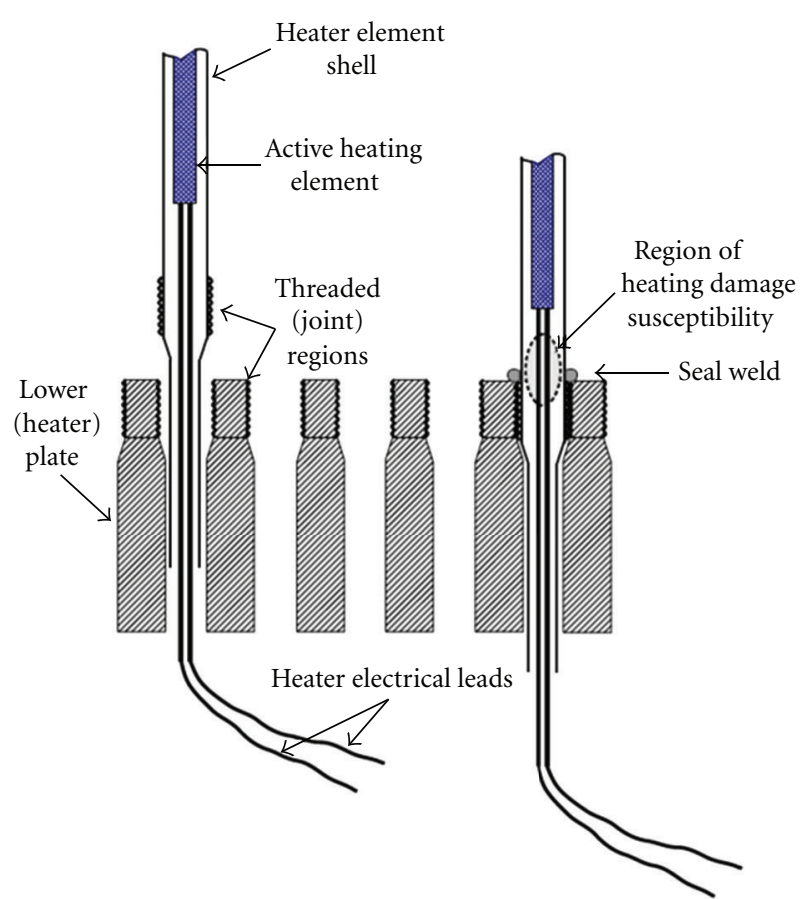

Figure 33: Sketch of original core design heater installation [12].

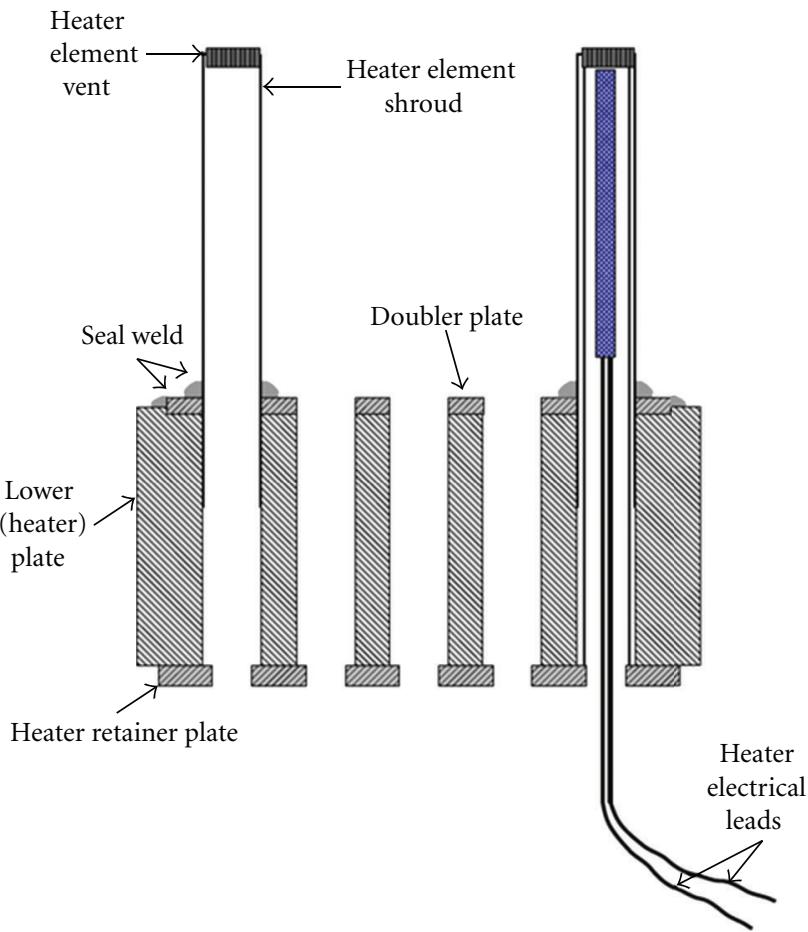

FIgURE 34: Sketch of modified core design heater installation [12].

In relation to the flow stability analyses, issues of interest are, for example, the investigation of primary flow rate versus heater power as a function of inlet subcooling, primary system pressure, and rate of heat removal by the SG; an investigation of primary loop fluid flow rate and its stability during long-term postaccident cooling conditions; an investigation of primary fluid flow stability during start up, maneuvering and shutdown transients.
In relation to the coupled containment-reactor vessel depressurization and emergency cooldown, issues of interest are, for example, a parametric investigation of the containment pressure behaviour and containment condensation during an automatic depressurization of the RPV; the analyses of the cooldown capability of the containment-reactor vessel coupling system by the helical coil SG; a parametric investigation of containment-reactor vessel pressure behaviour and containment condensation during a SBLOCA with or without the SG cooldown of the containment-reactor vessel coupled system.

Different parametric studies could be executed in the facility if its modifications are taken into account. An investigation of primary loop fluid flow rate and its stability as a function of heater power for various loop resistance condition, if through facility modification the loop resistance changes, could be of interest. By including in the facility a gravity FW tank, it is possible to study a parametric investigation of containment condensation and pressure behavior during a SBLOCA with a cooldown of the coupled containment-primary system using gravity-driven FW flow to the helical coil SG.

Considering the potential phenomena that could be investigated in this facility, an IAEA ICSP on "Integral PWR Design Natural Circulation Flow Stability and Thermo-hydraulic Coupling of Primary System and Containment During Accidents" is being hosted at OSU, and the experimental data will be collected at the OSU-MASLWR facility. The purpose of this IAEA ICSP is to provide experimental data on single-/two-phase flow instability phenomena under natural circulation conditions and coupled containment/reactor vessel behavior in integral-type light water reactors.

6.2. OSU-MASLWR Test Facility Core Modification Description. After the completion of the first test series, through a grant from the IAEA, the OSU-MASLWR test facility core was reconfigured [12] to eliminate a recurring grounding problem and improve facility reliability in anticipation of conducting the previous mentioned IAEA ICSP.

Figure 33 shows a sketch of original core design heater installation. The heater on the left is shown prior to seating into the lower heater plate. On right is view of an installed heater, indicating region of susceptibility of the electrical leads due to heat from the seal welding process.

Figure 34 shows a sketch of modified core design heater installation. The heater rod shroud on the left is inserted into the lower heater plate and seal welded prior to heater insertion from the bottom. On right is view of installed heater, held in heater shroud cavity by heater retainer plate.

Although a relatively minor modification to a complex and highly capable facility, both the availability for high power and rapid transient natural circulation phenomenology testing as well as the spectrum of operating transients that can be investigated using the test facility have been greatly improved $[12,15]$. OSU-MASLWR. In September 2006, a MASLWR Natural 


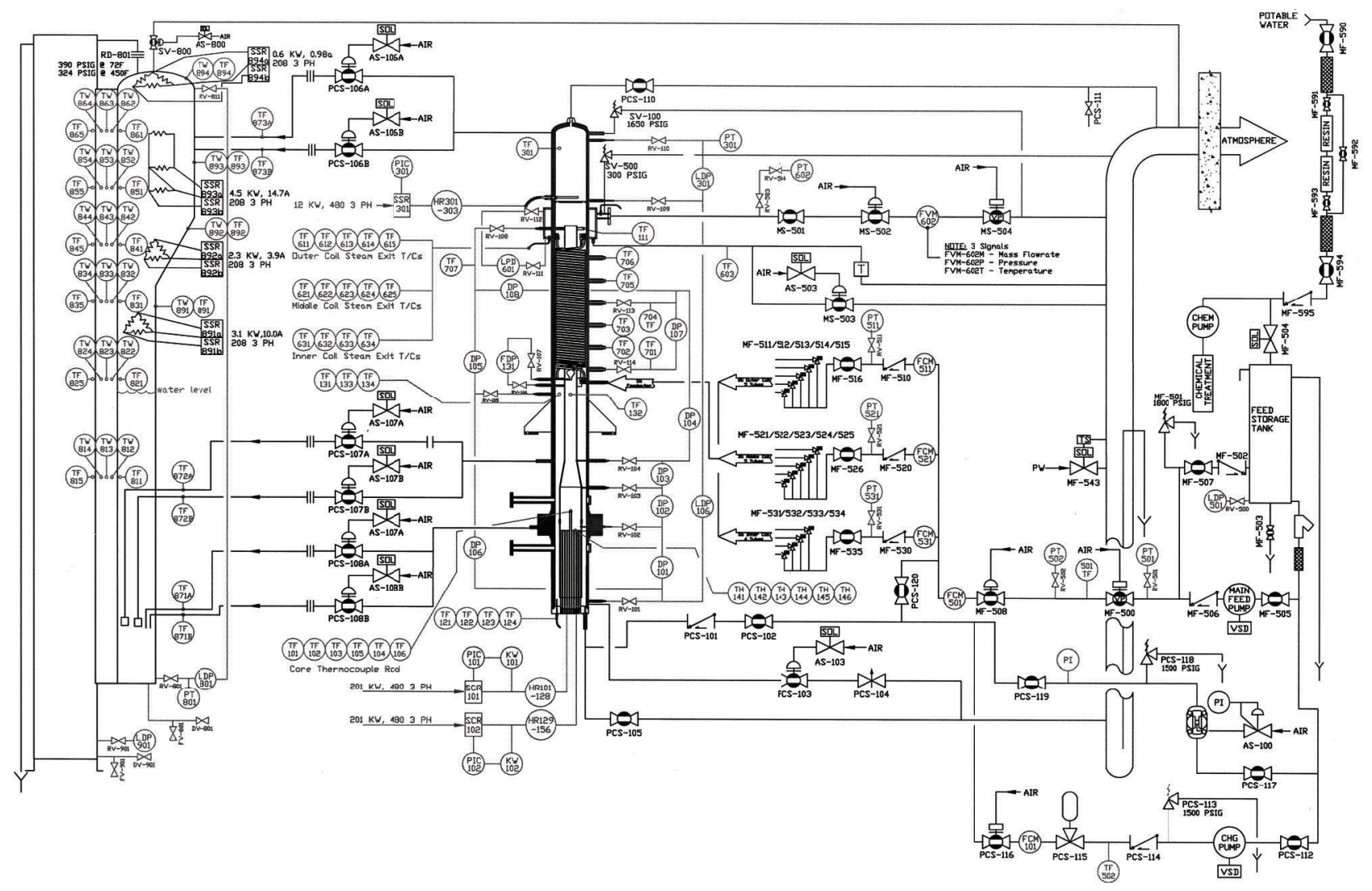

FIGURE 35: OSU-MASLWR test facility process and instrumentation diagram [20].

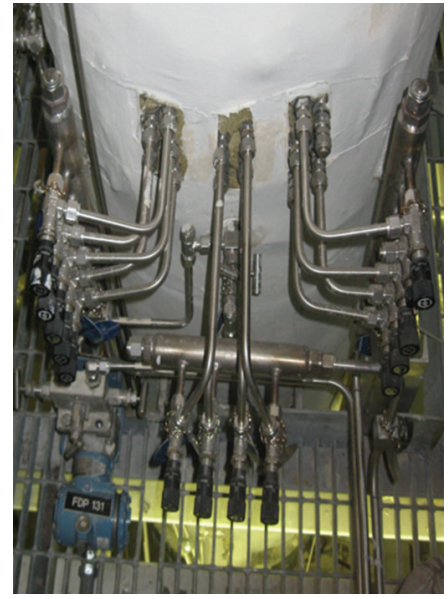

FIgURE 36: Photo of variable-position throttle valve located at the entrance of each helical coil.

Circulation Standard Problem Working Group was formed within the IAEA Coordinated Research Project (CRP) on Natural Circulation Phenomena, Modelling, and Reliability that Utilize Natural Circulation. Its purpose is to provide experimental data on flow instability phenomena under natural circulation conditions and coupled containment/reactor vessel behavior in integral-type reactors. A thermal hydraulic design test, ICSP test 1 , involving a stepwise reduction in primary mass inventory of the facility while operating at reduced power (decay power), and an integral system safety test, ICSP test 2, involving a loss of FW transient with subsequent ADS blowdown and long-term cooling will be executed. These data can be used to assess computer codes for reactor system design and analysis. The ICSP is being hosted at OSU, and the experimental data will be collected at the OSU-MASLWR $[1,2,14-16]$.

During the ICSP test 1 , twelve different primary side water levels will be investigated. A valve located in the draining line of the facility is opened in order to drain the facility to fixed primary level set points. Following the ICSP specification each step is maintained for approximately 45 minutes in order to reach steady-state conditions. The inventory will not be reduced more than the $35 \%$ in order to prevent the core from becoming uncovered. The main target of this test is to examine the effect of mass inventory reduction on natural circulation flow rate in the small integral PWRs providing data on single-/two-phase flow instability phenomena.

The main target of the ICSP test 2 is to provide data on containment/reactor vessel behavior in integral-type light water reactor by examining the blow-down transient into the containment in a small integral PWR as a results of normal ADS opening and the subsequent long-term cooling phase using the sump natural circulation. Considering the maximum HPC operating pressure, different actions for the ADS valves are taken into account.

The ICSP will be conduct in three different phases: a "double blind phase," a "blind phase," and a "open phase." 


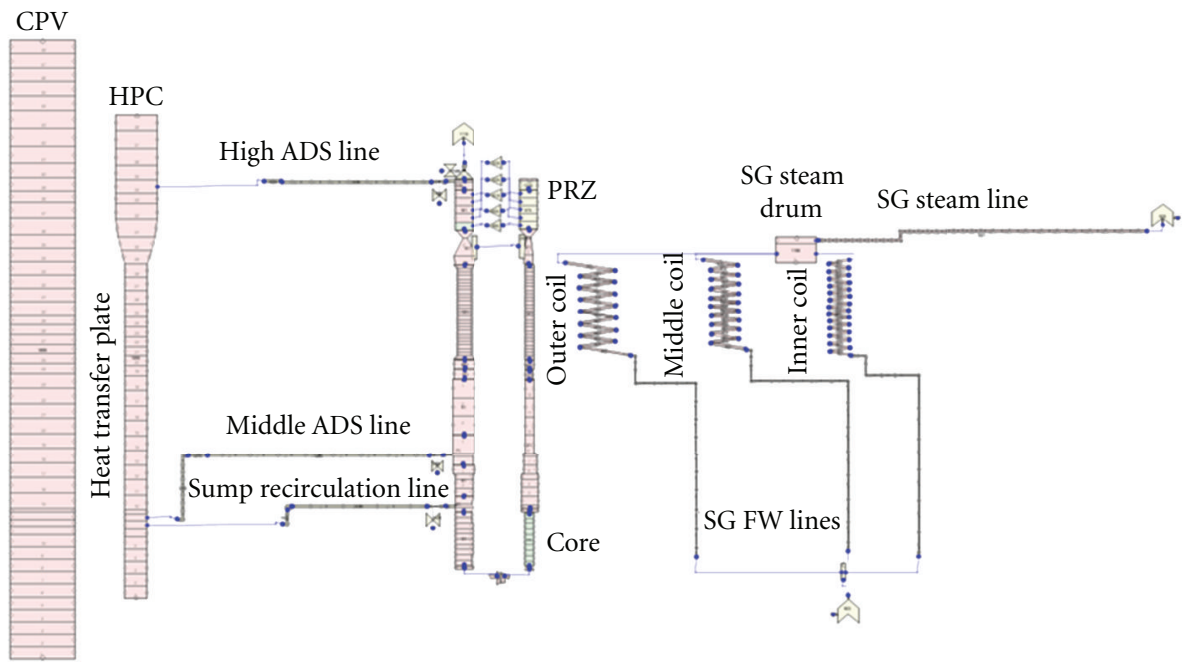

FIGURE 37: TRACE model developed for the participation at the IAEA ICSP [2, 25, 26].

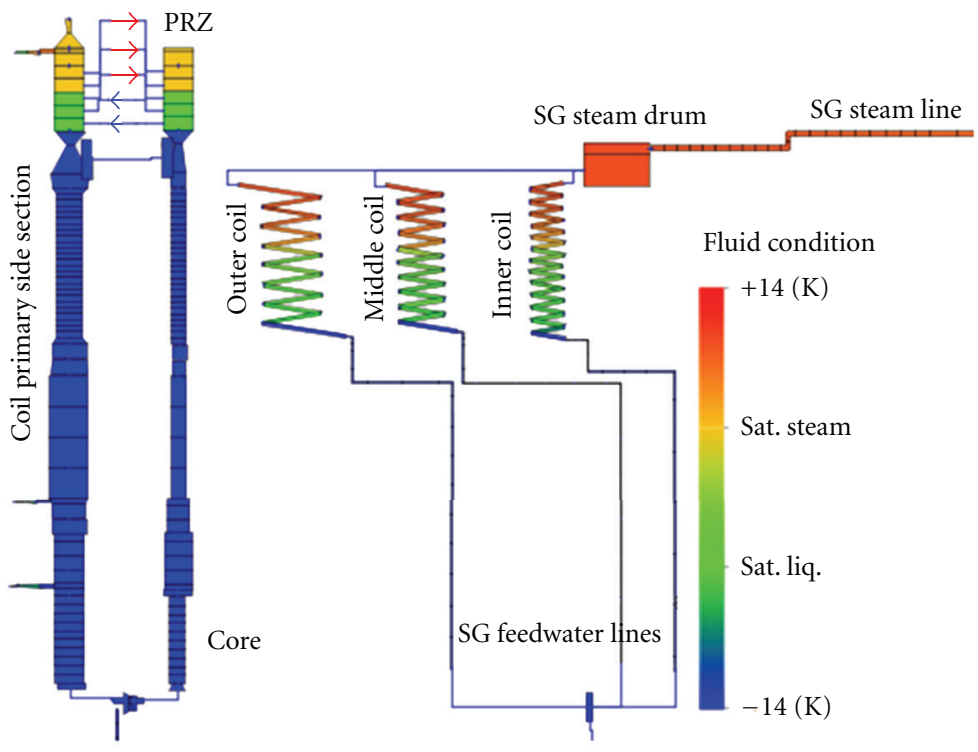

FIGURE 38: Facility fluid configuration, during the steady state analyses before the SOT of the ICSP test $1[2,25,26]$.

During the "double blind phase," the ICSP tests have not been performed yet, and only test procedures with the specification boundary and initial condition are available at the ICSP participation. Then the ICSP participant will submit the so-called "double blind calculations." During the "blind phase," the test will be already conducted and only some selected real initial and boundary conditions will be available at the ICSP participants. Then the ICSP participants will submit the "blind calculations." At the end, the experimental data will be disclosed to the ICSP participant that will submit the "open calculation."

A detailed updated OSU-MASLWR test facility process and instrumentation diagram, distributed in the ICSP framework, is reported in the Figure 35. Figure 36 shows a photo of the variable-position throttle valve located at the entrance of each helical to allow to increase the pressure drop of the different helical coil in order to increase the stability of the circuit and to close some coils.
A TRACE model developed to participate at the IAEA ICSP is shown in Figure 37 [26]. An animation model, developed by using SNAP, is shown in Figure 38 and represents the fluid condition configuration of the facility before the SOT of the ICSP test $1[2,25,26]$.

\section{Conclusions}

Oregon State University has constructed a system-level test facility to examine natural circulation phenomena of importance to MASLWR, a small modular integral PWR relying on natural circulation during both steady-state and transient operation.

Four tests have been conducted, in support of the MASLWR concept design verification, in the experimental facility. The MASLWR normal startup, the operation, and its shutdown are thermal hydraulically demonstrated. The behavior of the RPV and containment and their coupling is 
thermal hydraulically demonstrated during a design basis accident test, "inadvertent actuation of one middle ADS valve" (OSU-MASLWR-001), and during a beyond design basis accident test, "inadvertent actuation of one high containment ADS valve" (OSU-MASLWR-003B). During these two tests, the RPV level never fell below the top of the core.

Since the degree of the steam superheat is changed in order to control the facility, the primary system flow rates and secondary side steam superheat for a variety of core power levels and FW flow rate were collected in the OSUMASLWR-002 and 003A test.

Currently, considering the phenomena simulating capability of this facility, an IAEA ICSP on "Integral PWR Design Natural Circulation Flow Stability and Thermo-hydraulic Coupling of Primary System and Containment During Accidents" is being hosted at OSU and the experimental data will be collected at the OSU-MASLWR facility, to provide experimental data on single-/two-phase flow instability phenomena under natural circulation conditions and coupled containment/reactor vessel behavior in integral-type light water reactors.

Different analyses have been performed in order to analyze the capability of the best estimate thermal hydraulic system codes to predict the phenomena typical of the MASLWR prototype and their implication to its operation, thermal hydraulically characterized in the OSU-MASLWR facility. All the previous tests have been analyzed by using different best estimate thermal hydraulic system code. The results of the calculated data show that the selected best estimate thermal hydraulic system codes are in general able to qualitatively predict the phenomena typical of the MASLWR prototype design as the single- and two-phase natural circulation, the heat exchange from primary to secondary side by helical SG in superheated condition and primary/containment coupling. Considering the potential phenomena that can be investigated in the facility, the experimental data developed during the IAEA ICSP tests will be useful for the assessment of the thermal hydraulic codes for reactor system design and analysis of integral-type light water reactor.

In order to quantitatively evaluate the capability of these codes to simulate the OSU-MASLWR phenomena, and therefore use the calculated data for the code assessment, is necessary a code nodalization qualification against several facility operational characteristic like pressure drop at different primary mass flow rates and heat losses at different primary side temperatures. These experimental characterizations are currently under development in the ICSP framework.

Since the MASLWR prototype is the basis for the NuScale, Inc. reactor, the OSU-MASLWR experimental facility will be useful for the NuScale testing for safety and operation [29].

\section{Abbreviations}

ADS: $\quad$ Automatic depressurization system

AP600/1000: Advanced plant 600/1000 MWe

CAREM: Natural circulation-based PWR being developed in Argentina
CL: $\quad$ Cold leg

CRP: $\quad$ Coordinate research project

ESBWR: Economic simplified boiling water reactor

FW: $\quad$ Feedwater

HL: $\quad$ Hot leg

HPC: $\quad$ High-pressure containment

IAEA: International Atomic Energy Agency

ICSP: International Collaborative Standard Problem

IRIS: International Reactor Innovative and Secure

LOCA: Loss of coolant accident

LP: $\quad$ Lower plenum

MFW: $\quad$ Main feed water

MASLWR: Multi-application small light water reactor

MS: $\quad$ Main steam

OSU: $\quad$ Oregon State University

PRZ: $\quad$ Pressurizer

PWR: $\quad$ Pressurized water reactor

RPV: $\quad$ Reactor pressure vessel

SASM: $\quad$ Severe accident scaling methodology

SBLOCA: Small-break LOCA

SG: $\quad$ Steam generator

SOT: $\quad$ Start of transient

SMART: System integrated modular advanced reactor

SNAP: $\quad$ Symbolic nuclear analysis package

SWR-1000: Siedewasser reaktor, 1000 MWe

TRAC: Transient reactor analysis code

TRACE: TRAC/RELAP advanced computational engine

UP: $\quad$ Upper plenum

USNRC: US Nuclear Regulatory Commission

WWER: Water moderate, water-cooled energy reactor.

\section{References}

[1] F. Mascari, G. Vella, B. G. Woods, and F. D’Auria, "Analysis of the Multi-Application Small Light-Water Reactor (MASLWR) design natural circulation phenomena," in Proceedings of the International Congress on Advances in Nuclear Power Plants (ICAPP '11), Nice, France, May 2011.

[2] F. Mascari, G. Vella, and B. G. Woods, "TRACE code analyses for the IAEA ICSP on integral PWR design natural circulation flow stability and thermo-hydraulic coupling of containment and primary system during accidents," in Proceedings of the ASME Small Modular Reactors Symposium (SMR '11), Washington, DC, USA, September 2011.

[3] J. Cleveland, "Overview of Global Developments of Advanced Nuclear Power Plants,” Annex 1, Natural Circulation In Water Cooled Nuclear Power Plants Phenomena, Models, And Methodology For System Reliability Assessments, IAEA TECDOC 1474, November 2005.

[4] IAEA-TECDOC-1281, "Natural Circulation Data and Methods for Advanced Water Cooled Nuclear Power Plant Design," April 2000.

[5] IAEA TECDOD-1474, "Natural Circulation in Water Cooled Nuclear Power Plants," November 2005. 
[6] IAEA-TECDOC-1391, "Status of Advanced Light Water Reactor Designs 2004,” May 2004.

[7] F. Mascari, G. Vella, P. Buffa, A. Compagno, and E. Tomarchio, "Passive safety systems in view of sustainable development," Final Report on the Round Tables, Erasmus Intensive Programme Project (IP) ICARO Intensive Course on Accelerator and Reactor Operation, Sicilia, Italia.

[8] S. M. Modro, J. E. Fisher, K. D. Weaver et al., "Multi-Application Small Light Water Reactor Final Report. DOE Nuclear Energy Research Initiative Final Report," Idaho National Engineering and Environmental Laboratory, December 2003.

[9] J. N. Reyes Jr. and J. King, "Scaling Analysis for the OSU Integral System Test Facility," Department of Nuclear Engineering Oregon State University 116 Radiation Center Corvallis, OR 97331-5902 NERI Project 99-0129, Prepared For U.S. Department of Energy.

[10] J. N. Reyes Jr., "Integral System Experiment Scaling Methodology," Annex 11, Natural Circulation In Water Cooled Nuclear Power Plants Phenomena, Models, And Methodology For System Reliability Assessments, IAEA TECDOC 1474, November 2005 .

[11] J. N. Reyes Jr., J. Groome, B. G. Woods et al., "Testing of the multi-application small light water reactor (MASLWR) passive safety systems," Nuclear Engineering and Design, vol. 237, no. 18, pp. 1999-2005, 2007.

[12] M. R. Galvin, "OSU MASLWR Test Facility Modification Description Report," IAEA Contract Number USA-13386, Oregon State University, November, 2007.

[13] F. Mascari, G. Vella, B. G. Woods et al., "Sensitivity analysis of the MASLWR helical coil steam generator using TRACE," Nuclear Engineering and Design, vol. 241, no. 4, pp. 1137-1144, 2011.

[14] B. G. Woods and F. Mascari, "Plan for an IAEA International Collaborative Standard Problem on Integral PWR Design Natural Circulation Flow Stability and Thermo-Hydraulic Coupling of Containment and Primary System During Accidents," Department of Nuclear Engineering and Radiation Health Physics, Oregon State University, prepared for IAEA.

[15] B. G. Woods, M. R. Galvin, and B. C. Jordan, "Problem Specification for the IAEA International Collaborative Standard Problem on Integral PWR Design Natural Circulation Flow Stability and Thermo-Hydraulic Coupling Of Containment and Primary System During Accident," DRAFT.

[16] J. H. Choi, Second Workshop of IAEA ICSP on Integral PWR Design Natural Circulation Flow Stability and Thermo-hydraulic Coupling of Containment and Primary System during Accidents, Presentation, Vienna, Austria, March 2011.

[17] S. Levy, Two-Phase Flow in Complex Systems, Wiley-Interscience, New York, NY, USA, 1999.

[18] "An Integrated Structure and Scaling Methodology for Severe Accident Technical Issue Resolution," NUREG/CR-5809.

[19] N. Zuber, "Appendix D: Hierarchical, Two-Tiered Scaling Analysis," An Integrated Structure and Scaling Methodology for Severe Accident Technical Issue Resolution, U.S Nuclear Regulatory Commission, Washington, DC, USA, 20555, NUREG/CR-5809, November 1991.

[20] A. Weiss, J. Bowser, M. Galvin, and B. Woods, OSU MASLWR drawings. 2010.

[21] F. Mascari, G. Vella, B. G. Woods, M. Adorni, and F. D'Auria, "Analysis of the OSU-MASLWR natural circulation phenomena using TRACE code," in Proceedings of the Technical Meeting on Application of Deterministic Best Estimate Safety Analysis, University of Pisa, Pisa, Italy, September 2009, IAEA, organized in cooperation with the OECD Nuclear Energy Agency and the European Commission.

[22] F. Mascari, Natural circulation and phenomenology of boron dilution in the pressurzied water reactors (circolazione naturale e fenomenologie di boron dilution in reattori ad acqua in pressione), Ph.D. thesis, University of Palermo, 2010.

[23] J. Pottorf, F. Mascari, B. G. Woods et al., "TRACE, RELAP5 Mod 3.3 and RELAP5-3D code comparison of OSUMASLWR-001 test," in Proceedings of the American Nuclear Society Winter Meeting and Nuclear Technology Expo, vol. 101, Transactions of the American Nuclear Society, 2009.

[24] B. G. Woods, "Analysis of RELAP5-3D Modeling Techniques for Natural Circulation Small Integral Light Water Reactors," Department of Nuclear Engineering and Radiation Health Physics Oregon State University Prepared for NuScale, Inc., 2008.

[25] F. Mascari and G. Vella, "IAEA International Collaborative Standard Problem on Integral PWR Design Natural Circulation Flow Stability and Thermo-hydraulic Coupling of Containment and Primary System during Accidents Double Blind Calculation Results," Presentation, II Technical Meeting IAEA ICSP, March 2011.

[26] F. Mascari and G. Vella, "IAEA international collaborative standard problem on integral PWR design natural circulation flow stability and thermo-hydraulic coupling of containment and primary system during accidents double blind calculation results," Tech. Rep., Dipartimento dell'Energia, Università degli Studi di Palermo, Palermo, Italy, February 2011, Prepared for International Atomic Energy Agency.

[27] F. Mascari, B. G. Woods, and M. Adorni, "Analysis, by TRACE Code, of natural circulation phenomena in the MASLWROSU-002 test," in Proceedings of the International Conference Nuclear Energy for New Europe, Portoroz, Slovenia, September 2008.

[28] F. Mascari, G. Vella, B. G. Woods et al., "Sensitivity analysis of the MASLWR helical coil steam generator using TRACE," in Proceedings of the International Conference Nuclear Energy for New Europe, Bled, Slovenia, September 2009.

[29] NuScale's Passive Safety Approach, Presentation, NuScale Power, Inc. April 2011, http://www.nuscalepower.com/otNuclear-Power-Presentations.php. 

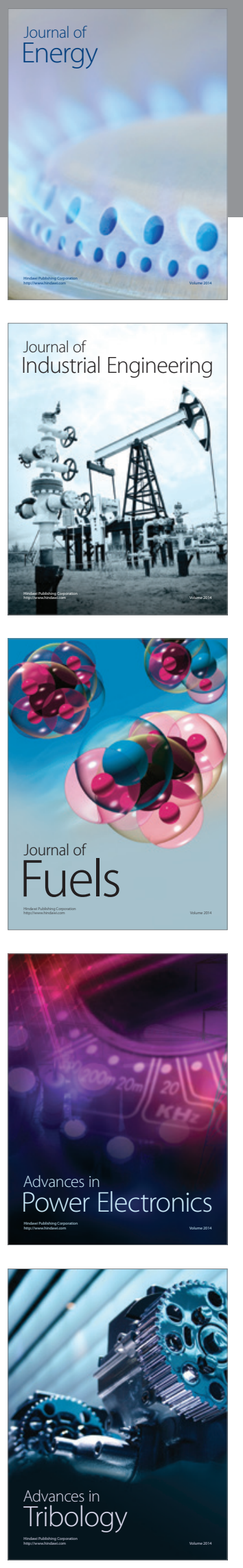
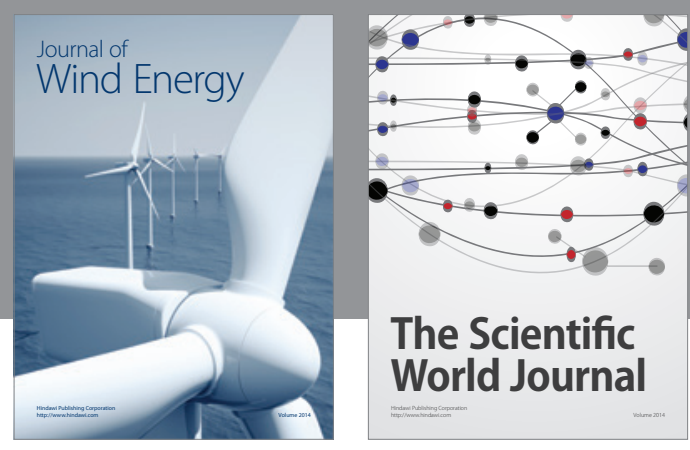

The Scientific World Journal

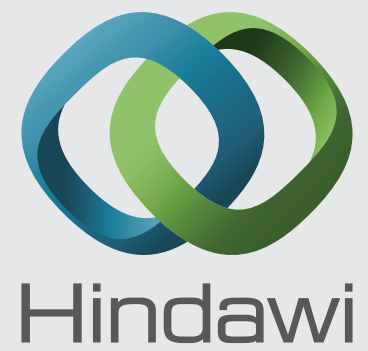

Submit your manuscripts at http://www.hindawi.com
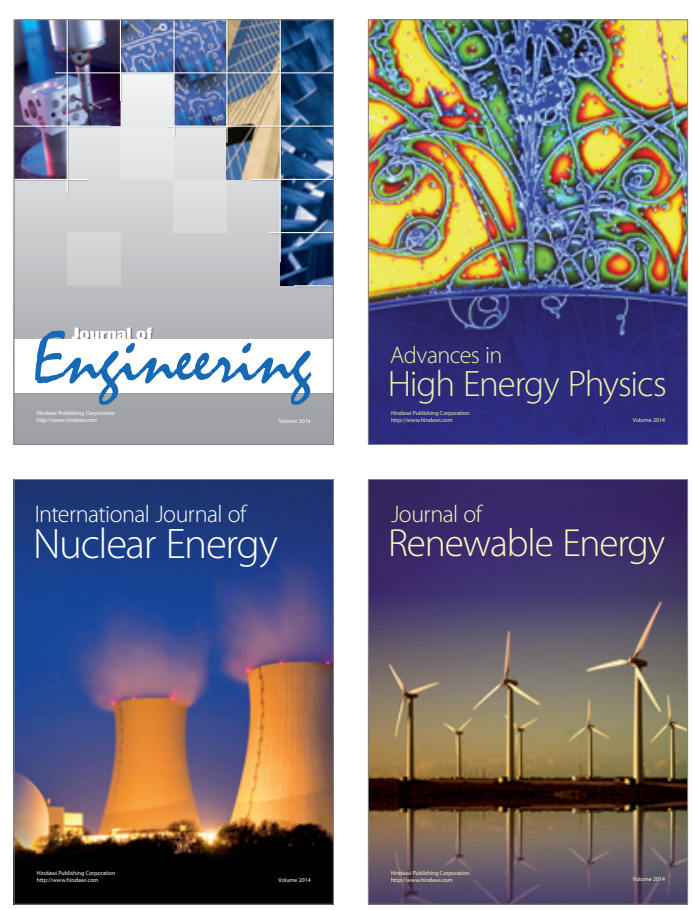

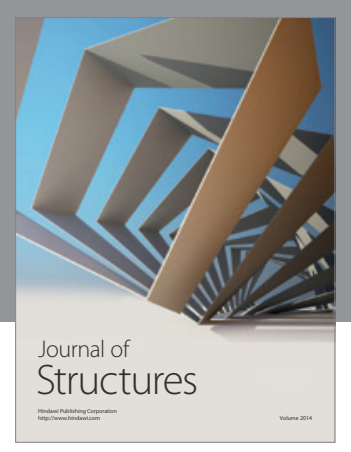

Rotating
Mechinery
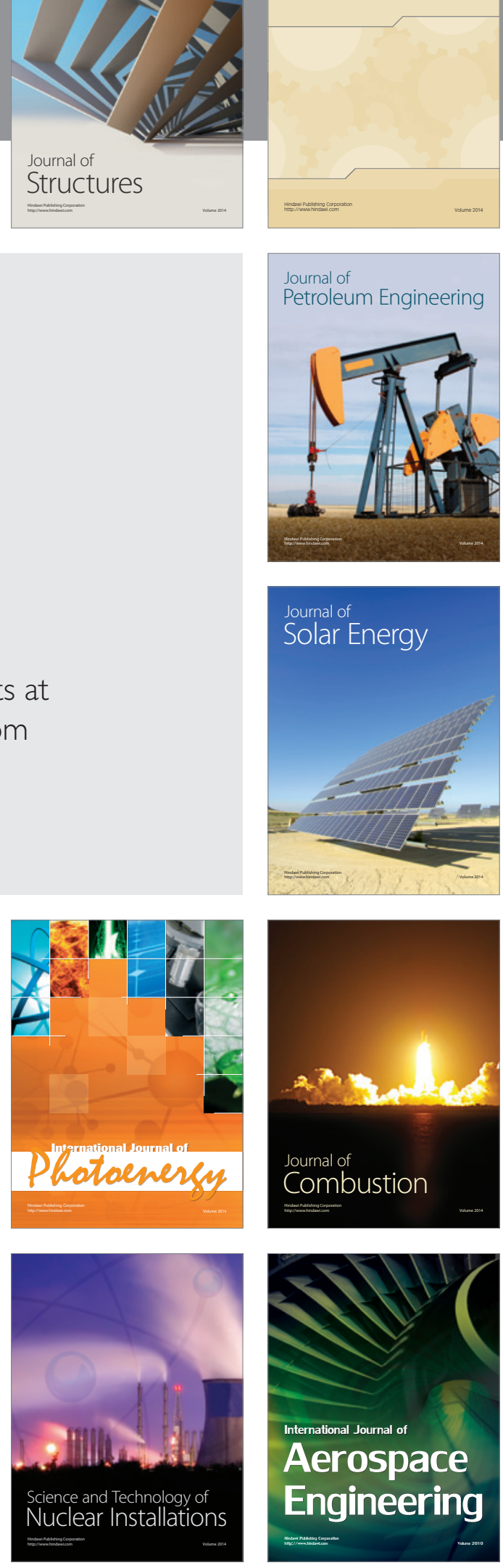